\title{
\begin{tabular}{l|l} 
Mibraries & DSpace@MIT
\end{tabular}
}

\author{
MIT Open Access Articles
}

Sensory Arrays of Covalently Functionalized SingleWalled Carbon Nanotubes for Explosive Detection

The MIT Faculty has made this article openly available. Please share how this access benefits you. Your story matters.

Citation: Schnorr, Jan M., Daan van der Zwaag, Joseph J. Walish, Yossi Weizmann, and Timothy M. Swager. "Sensory Arrays of Covalently Functionalized Single-Walled Carbon Nanotubes for Explosive Detection.” Advanced Functional Materials 23, no. 42 (November 13, 2013): 5285-5291.

As Published: http://dx.doi.org/10.1002/adfm.201300131

Publisher: Wiley Blackwell

Persistent URL: http://hdl.handle.net/1721.1/84616

Version: Author's final manuscript: final author's manuscript post peer review, without publisher's formatting or copy editing

Terms of use: Creative Commons Attribution-Noncommercial-Share Alike 3.0 
DOI: 10.1002/adma.((please add manuscript number))

\section{Sensory Arrays of Covalently Functionalized Single-Walled Carbon Nanotubes for Explosive Detection}

By Jan M. Schnorr, Daan van der Zwaag, Joseph J. Walish, Yossi Weizmann, and Timothy M. Swager*

[*] Prof. T. M. Swager, Dr. J. M. Schnorr, D. van der Zwaag, Dr. J. J. Walish, Prof. Y. Weizmann

Department of Chemistry

Massachusetts Institute of Technology

Cambridge, MA 02139 (USA)

E-mail: tswager@mit.edu

D. van der Zwaag

present address: Department of Chemical Engineering and Chemistry

Eindhoven University of Technology

$5600 \mathrm{MB}$ Eindhoven (The Netherlands)

Prof. Y. Weizmann

present address: Department of Chemistry

The University of Chicago

Chicago, IL 60637 (USA)

Keywords: sensors, explosive detection, carbon nanotubes, thiourea

The real-time detection of explosive compounds and markers for explosive compounds represents an ongoing challenge for gas sensor development. Explosive-based weapons remain the preferred tools of terrorism and it is likely that this threat will be a continuing concern to society for the foreseeable future. ${ }^{[1]}$ It is therefore desirable to develop sensors capable of detecting the vapors emanating from explosives. The number of compounds that can serve as vapor signatures of explosives is considerable and goes beyond well-known highly energetic compounds such as RDX, PETN, and TNT. For example, nitromethane is a common solvent but can be utilized in the formation of explosives mixtures. ${ }^{[2]}$ Similarly a non-explosive vapor marker of some plastic explosives is cyclohexanone, which is used to recrystallize the explosive $\mathrm{RDX} .^{[3]}$ As a result of its significantly higher vapor pressure, residual cyclohexanone is recognized as a marker for RDX based explosives. ${ }^{[4]}$ Several 
Submitted to

\section{ADVANCED}

techniques have been used to detect these analytes including ion mobility spectrometry (IMS), mass spectrometry (MS), and gas chromatography (GC). Although these methods can provide sensitivity and selectivity, the instrumentation is bulky, costly, and can be complex to operate. It is therefore desirable to develop low-cost sensors compatible with portable platforms that are readily integrated into existing electronic systems. Carbon nanotube (CNT) based chemiresistors are an emerging class of sensors that fulfill these requirements and are displaying promising performance in a variety of sensing applications. ${ }^{[5,6]} \mathrm{CNT}$ chemiresistors can be deposited between electrodes by evaporation of dispersions, or can be effectively drawn from compressed CNT solids. ${ }^{[7]}$ In order to improve the selectivity of CNT-based sensors for certain analytes, functionalization with selectors (groups designed to interact selectively with particular molecules) is usually required. This can be done by non-covalent functionalization with selector molecules with pendant pyrenes, ${ }^{[8]}$ wrapping with functionalized polymers, ${ }^{[9]}$ or by covalent functionalization of the sidewalls or the carboxylates found at the termini of oxidized CNTs. ${ }^{[10]}$ A variety of selector types have been developed, ranging from chemically synthesized selectors that rely on polarity or acid-base interactions to enzymes for greater specificity. ${ }^{[5,11]}$

To create SWCNTs capable of selective detection of nitromethane and cyclohexanone vapors we have prepared a family of selectors that should provide specific interactions. Inspired by their capabilities for anion sensing in solution, we chose to investigate thiourea, urea, and squaramide groups which have been reported to interact strongly with nitrates, carboxylates and other compounds that resemble the structure of our target $\mathrm{R}-\mathrm{NO}_{2}$ and ketone analytes. ${ }^{[12]}$ We chose a two-step attachment strategy. First, amino groups were covalently attached to the sidewall of single-walled CNTs (SWCNTs) via thermal aziridination. ${ }^{[13]}$ The resulting $\mathrm{NH}_{2}$ SWCNTs were then reacted with a second reagent containing the desired selector. This twostep approach combines an established and reliable CNT functionalization method with the flexibility of using pendant amines to attach a variety of groups in the second step. It is 
important to note that covalent functionalization of the sidewalls disrupts the extended electronic states of SWCNTs and thereby increases the base resistance more than a noncovalent functionalization approach. An increased base resistance has the effect of lowering the sensitivity for the detection of analyte-induced resistance increases. Nevertheless, with modest degrees of functionalization, quality sensors have been obtained from covalently functionalized SWCNTs. ${ }^{[10 b, 14]}$ An important advantage of covalent functionalization is that it produces a more durable sensor relative to non-covalent compositions that are prone to changes in structure, which can lead to CNT/selector phase separation and decreased sensor performance.

Using the two-step synthetic route, substituted thiourea and squaramide groups were attached to the surface of SWCNTs (Fig. 1a). After confirming the successful introduction of the selector by X-ray photoelectron spectroscopy (XPS), sensors were fabricated from the functionalized SWCNTs by drop-casting the sensing material between two electrodes (Fig. 1b). The sensor was loaded into an enclosure and a gas stream of either pure nitrogen or nitrogen containing an analyte vapor was passed over the device. A constant potential of 0.1 $\mathrm{V}$ was applied across the sensor and the relative current change when switching from pure nitrogen to the nitrogen-analyte mixture was recorded. Among the tested sensors, $\mathbf{m}-\mathbf{C F}_{\mathbf{3}} \mathbf{- B n}$ TU-SWCNT led to the most pronounced sensing response of $0.9 \%$ when exposed to $57 \mathrm{ppm}$ cyclohexanone (Fig. 1c) and no clear response was observed for the squaramide-based sensors (see supporting information). We attribute the higher performance of $\mathbf{m}-\mathbf{C F}_{\mathbf{3}}-\mathbf{B n}-\mathbf{T U}-$ SWCNT to the more acidic nature of NH protons in thiourea groups relative to those of the squaramide, and this increased acidity is further augmented by the electron poor benzyl substituent. Additionally, the highly reactive isothiocyanate reagent, which was used to introduce this selector, resulted in a higher functional group density of the thiourea groups as compared to their squaramide counterparts (see Fig. 1a for functional group densities by XPS). 


\section{ADVANCED}

Encouraged by these initial results, we investigated related receptors with the goal to further improve the sensing performance. Phenyl substituted selectors were included to probe both the effects of steric demand and electron affinity of the substituent. Additionally, we decided to investigate a selector containing two thiourea units in close proximity, which could potentially lead to a higher binding affinity of the selector to its analyte by chelation. ${ }^{[15,16]}$ Selector 9 is synthesized from diamine 5 and isothiocyanate 7 (Fig. 2a). Although thiourea units have shown better interactions with analytes in previous studies, ${ }^{[12]}$ it was not clear in this particular case if the steric bulk of the sulfur atoms would prevent a planar conformation in 9 and thereby compromise the binding of the selector to target analytes. As a result we also investigated $\mathbf{8}$, the urea counterpart of 9 .

A challenge when investigating the performance of different selectors in CNT-based sensors is the complex dependence of the sensing response on a variety of contributing factors. Ideally the interaction of analyte and selector creates maximal resistance changes, but this performance is highly dependent on the selector attachment, their density on the CNT surface, and other functionality/structures present in the CNTs that is introduced in the synthesis or processing. To separate the effect of CNT attachment from the recognition performance of the selector, we performed a ${ }^{1} \mathrm{H}$ NMR binding study with model selectors and cyclohexanone in solution. The association constants for cyclohexanone and the model receptors in $\mathrm{CDCl}_{3}$ obtained from these studies showed a clear advantage of the bidentate thiourea receptor over its analogues with only one binding site (see Fig. 2a for the measured association constants). Interestingly, the ${ }^{1} \mathrm{H}$ NMR data from the titration experiment with 9 revealed no significant change in chemical shift for the NH protons further away from the central benzene ring upon addition of cyclohexanone (labeled $\mathbf{a}$ and $\mathbf{b}$ in Fig. 2a, see supporting information for NMR data). The inner NH protons on the other hand (c and $\mathbf{d}$ in Fig. 2) experienced a significant downfield shift with increasing cyclohexanone concentrations. This suggests that the ketone participates in hydrogen bonding with one proton of each thiourea unit in 9 instead of binding 
Submitted to

\section{ADVANCED}

to both NH protons of either thiourea group. Unfortunately, no association constant could be determined for $\mathbf{8}$, because the compound displayed very limited solubility in $\mathrm{CDCl}_{3}$, presumably as a result of strong intermolecular hydrogen bonding.

Guided by our initial sensing experiments as well as the ${ }^{1} \mathrm{H}$ NMR binding study, three additional selectors were attached to SWCNTs: the urea-based selector with two binding sites (Bis-U-SWCNT), its thiourea counterpart (Bis-TU-SWCNT), and the phenyl analogue of m$\mathrm{CF}_{3}-\mathrm{Bn}-\mathrm{TU}-\mathrm{SWCNT}$ (m-CF $-\mathrm{Ph}-\mathrm{TU}-\mathrm{SWCNT}$ ) (Fig. 2b). Additionally, m-CF - Bn-TUSWCNT, m-CF $-\mathbf{F}_{\mathbf{3}}-\mathrm{Bn}-\mathrm{SQ}$-SWCNT, and pristine (unfunctionalized) SWCNTs were included in further tests for comparison. To expose all sensors to exactly the same conditions, we developed a platform for the simultaneous measurement of several sensors. Glass slides having sensor arrays were connected to an array potentiostat through an edge connector and placed in a custom enclosure fabricated from tetrafluoroethylene. The analyte gas could then be applied to all sensors while the current was recorded at a constant potential (see Supporting Information for details).

These sensor arrays were exposed to 57 and 283 ppm cyclohexanone $(1.3 \%$ and $6.3 \%$ of the equilibrium vapor concentration at $\left.25^{\circ} \mathrm{C}\right)$ as well as 57,283 and $469 \mathrm{ppm}$ nitromethane $(0.1 \%$, $0.6 \%$, and $1 \%$ of the equilibrium vapor concentration at $25^{\circ} \mathrm{C}$ ) for evaluation of the chemiresistive properties (Fig. 3a). To determine the reproducibility, two copies of each sensor were included on each glass slide and each exposure to the analyte was repeated five times. Using this data, the average response of each sensor type to the analytes at each concentration was determined (Fig. 3b).[17] The results show that $\mathbf{C F}_{\mathbf{3}}-\mathbf{B n}-\mathbf{S Q}$-SWCNT and Bis-TU-SWCNT are best suited for measurement of nitromethane while Bis-U-SWCNT performed best in the detection of cyclohexanone. The response to $283 \mathrm{ppm}$ cyclohexanone was ca. 20\% higher when using Bis-U-SWCNT compared to $\mathbf{m}-\mathbf{C F}_{\mathbf{3}}-\mathbf{B n}-\mathbf{T U}-\mathbf{S W C N T}$, which displayed the best performance in the first round of testing. An increase in sensing response to 469 ppm nitromethane of 30\% was observed when using Bis-TU-SWCNT 


\section{Submitted to}

\section{ADVANCED}

compared to $\mathbf{m}-\mathbf{C F}_{\mathbf{3}}-\mathbf{B n}-\mathbf{T U}-\mathbf{S W C N T}$. This improvement only required a simple additional synthetic step for the preparation of a new selector. One interesting aspect is that pristine SWCNTs show a significant response to cyclohexanone and a minimal response to nitromethane vapor.

Upon closer inspection of the sensing traces for each type of functionalized SWCNTs, it is evident that the responses of duplicate sensors using the same selector are virtually superimposable (see overlay of two sensing traces in each line of Fig. 3a). This high level of reproducibility is remarkable considering that no special precautions were taken when preparing the sensors other than ensuring the sensors have base resistances that are the same order of magnitude.

To better evaluate selectivity, sensors were exposed to a variety of analytes and the resulting responses were analyzed using principle component analysis (PCA). PCA showed clustering of the responses for each analyte, which is remarkable considering the high similarity of the investigated receptors (Fig. 4a). Adding different classes of selectors to an array is certain to improve sensor selectivity and will be investigated in future studies.

We also have performed initial studies that address sensor-to-sensor reproducibility as well as the long-term stability. These aspects are of critical importance if this platform is to ever be considered for commercial applications. The response of three separate sensors based on $\mathbf{m}-$ CF $_{3}$-Bn-TU-SWCNT to 57 and 283 ppm cyclohexanone was first evaluated shortly after their fabrication (Fig. 4b). The sensor-to-sensor variance, although small, is much larger than we observe in our duplicate sensors on a given array. As a result, it is likely that these variations are mainly a result of the experimental setup, which includes the connectors, sample enclosure, and gas delivery. Subsequently, one of the devices was retested after 16 days as well as after 236 days of bench top storage under ambient conditions without special precautions (Fig. 4c). The response was reduced after the nearly eight months period, but a clear signal upon exposure to $57 \mathrm{ppm}$ of cyclohexanone could still be observed. We view 
these results as encouraging and suggest that with further development this sensor platform may be capable of producing sensors with small-enough drift to be viable for real-world applications.

In summary, we have developed SWCNT-based gas sensors with sensitivity to cyclohexanone and nitromethane, two compounds relevant for the detection of explosives. These resistivitybased sensing schemes have great potential as a result of simple fabrication, miniaturization, and facile integration into electronic circuits. Guided by initial sensing tests and ${ }^{1} \mathrm{H}$ NMR binding studies, improved selectors were synthesized and attached to SWCNTs to provide superior sensing performance. As a result, schemes involving the covalent attachment of selectors have promise for the systematic development of sensors for a wide range of analytes. The sensors showed a very high level of reproducibility between measurements with the same sensor and across different sensors of the same type. Furthermore, they exhibit promising long-term stability suitable for practical applications.

\section{Experimental}

Materials and Synthetic Manipulations: Synthetic manipulations were carried out under an argon atmosphere using standard Schlenk techniques. Single-walled carbon nanotubes were purchased from Southwest Nanotechnologies (SWeNT® CG100). All other chemicals were purchased from Sigma Aldrich and used as received. NMR spectra were recorded on Bruker Avance-400 spectrometers.

XPS Measurements: XPS spectra were recorded on a Kratos AXIS Ultra X-ray Photoelectron Spectrometer. The samples were drop-cast onto $\mathrm{SiO}_{2} / \mathrm{Si}$ substrates for the measurements. $\mathrm{NH}_{2}-\mathrm{SWCNT}$ : SWCNTs (150 mg, $\left.12.5 \mathrm{mmol} \mathrm{C}\right)$ were added to a flame dried Schlenk flask. 3-azidopropan-1-amine (6 g, $60 \mathrm{mmol})$ and 1,2-dichlorobenzene $(30 \mathrm{~mL})$ were added. The mixture was sonicated for $15 \mathrm{~min}$ and then equipped with a reflux condenser and stirred at $160{ }^{\circ} \mathrm{C}$ for $42 \mathrm{~h}$. The solvent was distilled off and the residue was washed on a $0.2 \mu \mathrm{m}$ 


\section{Submitted to

fluoropore filter membrane with $\mathrm{CH}_{2} \mathrm{Cl}_{2}$, methanol, ethanol, water, methanol, and hexanes.

The product was dried in vacuo. N/C ratio by XPS (based on N 1s vs. C 1s): $16.7 \%$ (functional group density: $8.3 \%$ ).

m-CF3-Bn-TU-SWCNT: $\mathrm{NH}_{2}$-SWCNT (20 mg) were sonicated for $15 \mathrm{~min}$ in ethanol $(15 \mathrm{~mL})$. 1-(isothiocyanatomethyl)-3,5-bis(trifluoromethyl)benzene (256 mg, $1.0 \mathrm{mmol})$ in ethanol $(5 \mathrm{~mL})$ was added dropwise at $0{ }^{\circ} \mathrm{C}$. The mixture was stirred for $48 \mathrm{~h}$. The solid was collected by filtration and the product was washed on a filter with ethanol, $\mathrm{CH}_{2} \mathrm{Cl}_{2}$, methanol, water, methanol, and hexanes and subsequently dried in vacuo. Functional group density based on F 1s and C 1s signals by XPS: 45 CNT carbon atoms per functional group. Other thiourea derivatives were obtained following a similar procedure (see supporting information). m-CF3-Bn-SQ-SWCNT: $\mathrm{NH}_{2}$-SWCNT $(17.5 \mathrm{mg})$ were sonicated for $15 \mathrm{~min}$ in ethanol (15 mL). 3-(3,5-bis(trifluoromethyl)benzylamino)-4-ethoxycyclobut-3-ene-1,2-dione (319 mg, $0.87 \mathrm{mmol})$ in ethanol $(15 \mathrm{~mL})$ was added. The mixture was stirred for $48 \mathrm{~h}$ at r.t. and subsequently for $48 \mathrm{~h}$ at $40{ }^{\circ} \mathrm{C}$. The solid was collected by filtration and the product was washed on a filter with ethanol, $\mathrm{CH}_{2} \mathrm{Cl}_{2}$, methanol, water, methanol, and hexanes and subsequently dried in vacuo. Functional group density based on F 1s and C 1s signals by XPS: 131 CNT carbon atoms per functional group. Other squaramide derivatives were obtained following a similar procedure (see supporting information). m-CF3-Ph-TU-SWCNT: $\mathrm{NH}_{2}$-SWCNT (20 mg) were sonicated for $2 \mathrm{~min}$ in $15 \mathrm{~mL}$ THF. 1isothiocyanato-3,5-bis(trifluoromethyl)benzene $(271 \mathrm{mg}, 1.0 \mathrm{mmol})$ was added and the mixture was stirred at r.t. for 3 days. The solid was collected by filtration and the product was washed on a filter with ethanol, $\mathrm{CH}_{2} \mathrm{Cl}_{2}$, methanol, water, methanol, and hexanes and subsequently dried in vacuo. Functional group density based on F 1s and C 1s signals by XPS: 180 CNT carbon atoms per functional group.

Methyl 3,4-bis(3-(3,5-bis(trifluoromethyl)phenyl)ureido)benzoate 8: 6 (2.81 g, $11.0 \mathrm{mmol})$ was added to 5 ( $831 \mathrm{mg}, 5.0 \mathrm{mmol})$ in $30 \mathrm{~mL}$ THF. The mixture was stirred at r.t. for $24 \mathrm{~h}$ 
Submitted to

\section{ADNANEDS
MATERRALIS}

after which the solvent was removed in vacuo. The crude product was recrystallized from

DCM (100 mL) and dried in vacuo. Yield: $2.17 \mathrm{~g}$ (3.2 mmol, 64\%). ${ }^{1} \mathrm{H}$ NMR (400 MHz, DMSO-d $6, \delta): 9.95(\mathrm{~s}, 1 \mathrm{H}), 9.78(\mathrm{~s}, 1 \mathrm{H}), 8.55(\mathrm{~s}, 1 \mathrm{H}), 8.39(\mathrm{~s}, 1 \mathrm{H}), 8.09(\mathrm{~d}, 4 \mathrm{H}, J=18.4 \mathrm{~Hz})$ $8.03(\mathrm{~d}, 1 \mathrm{H}, J=1.2 \mathrm{~Hz}), 7.93(\mathrm{~d}, 1 \mathrm{H}, J=8.8 \mathrm{~Hz}), 7.76(\mathrm{dd}, 1 \mathrm{H}, J=8.4 \mathrm{~Hz}, 2.0 \mathrm{~Hz}), 7.61(\mathrm{~d}$, $2 \mathrm{H}, J=8.4 \mathrm{~Hz}), 3.81(\mathrm{~s}, 3 \mathrm{H}) .{ }^{13} \mathrm{C}-\mathrm{NMR}\left(100 \mathrm{MHz}, \mathrm{DMSO}-d_{6}, \delta\right): 166.3(\mathrm{~s}), 154.0(\mathrm{~s}), 153.1$ (s), 142.5 (s), 142.1 (s), 138.0 (s), 131.4 (q, $J=32.5 \mathrm{~Hz}), 131.3$ (q, $J=32.5 \mathrm{~Hz}), 129.9$ (s), 127.6 (s), 127.3 (s), 125.4 (s) 123.9 (q, $J=271.1 \mathrm{~Hz}), 123.9$ (q, $J=270.9 \mathrm{~Hz}), 123.1$ (s), 119.8 (s), 118.7 (s), 115.2 (s), 52.7 (s). HRMS calc. for $\mathrm{C}_{26} \mathrm{H}_{16} \mathrm{~F}_{12} \mathrm{~N}_{4} \mathrm{O}_{4}[\mathrm{M}+\mathrm{H}]^{+}$: 677.1053, found: $677.1073 .[\mathrm{M}+\mathrm{H}]^{+}$

Methyl 3,4-bis(3-(3,5-bis(trifluoromethyl)phenyl)thioureido)benzoate 9: 7 (2.98 g, 11.0 mmol) was added to 5 ( $831 \mathrm{mg}, 5.0 \mathrm{mmol})$ in $30 \mathrm{~mL}$ THF. The mixture was stirred at r.t. for $22 \mathrm{~h}$ after which 7 ( $1 \mathrm{~g}, 3.7 \mathrm{mmol})$ was added. After stirring for two additional hours, the solvent was removed in vacuo. The crude product was washed with hexanes and DCM. Yield: $941 \mathrm{mg}(27 \%) .{ }^{1} \mathrm{H}-\mathrm{NMR}\left(400 \mathrm{MHz}, \mathrm{DMSO}_{6}, \delta\right): 10.39$ (s, 1H), 10.32 (s br, 1H), 10.02 (s, 1H), 9.91 (s br, 1H), 8.17 (d, 2H, $J=4.4 \mathrm{~Hz}), 8.06$ (d, $1 \mathrm{H}, J=1.6 \mathrm{~Hz}), 7.91$ (dd, $1 \mathrm{H}, J=8.4$ Hz, $2.0 \mathrm{~Hz}), 7.76$ (s br, 2H), $7.74(\mathrm{~d}, 1 \mathrm{H}, J=8.4 \mathrm{~Hz}), 3.88$ (s, 3H). HRMS calc. for $\mathrm{C}_{26} \mathrm{H}_{16} \mathrm{~F}_{12} \mathrm{~N}_{4} \mathrm{O}_{2} \mathrm{~S}_{2}[\mathrm{M}+\mathrm{H}]^{+}:$709.0596, found: 709.0611. [M+H] $]^{+}$ Bis-U-SWCNT: $\mathrm{NH}_{2}$-SWCNT (20 mg) were sonicated for $5 \mathrm{~min}$ in ethanol (15 mL). 9 (709 $\mathrm{mg}, 1.0 \mathrm{mmol}$ ) was added and the mixture was refluxed for 4 days. The solid was collected by filtration and the product was washed on a filter with ethanol, water, ethanol, $\mathrm{CH}_{2} \mathrm{Cl}_{2}$, and hexanes and subsequently dried in vacuo. Functional group density based on F $1 \mathrm{~s}$ and $\mathrm{C} 1 \mathrm{~s}$ signals by XPS: $130 \mathrm{CNT}$ carbon atoms per functional group.

Bis-TU-SWCNT: $\mathrm{NH}_{2}$-SWCNT (20 mg) were sonicated for $5 \mathrm{~min}$ in ethanol (15 mL). 8 (676 $\mathrm{mg}, 1.0 \mathrm{mmol}$ ) was added and the mixture was refluxed for 4 days. The solid was collected by filtration and the product was washed on a filter with ethanol, water, ethanol, $\mathrm{CH}_{2} \mathrm{Cl}_{2}$, and 
Submitted to

\section{ADNANCES
MAATRRALIS}

hexanes and subsequently dried in vacuo. Functional group density based on F $1 \mathrm{~s}$ and $\mathrm{C} 1 \mathrm{~s}$ signals by XPS: 100 CNT carbon atoms per functional group.

Device preparation: Glass slides (VWR Microscope Slides) were cleaned by ultrasonication in acetone for $10 \mathrm{~min}$, and after drying they were subjected to UV radiation in a UVO cleaner (Jelight Company Inc.) for $3 \mathrm{~min}$. Using an aluminum mask, layers of chromium (10 nm) and gold $(75 \mathrm{~nm})$ were deposited leaving a $1 \mathrm{~mm}$ gap using a metal evaporator purchased from Angstrom Engineering with home built aluminum shadow masks.

Pristine SWCNTs were added to $\mathrm{CH}_{2} \mathrm{Cl}_{2}$ at a concentration of $1 \mathrm{mg}$ per $5 \mathrm{~mL}, \mathrm{NH}_{2}-\mathrm{SWCNTs}$ were added to ethanol and all other functionalized SWCNTs were added to 1:1 mixtures of $\mathrm{CH}_{2} \mathrm{Cl}_{2}$ /iso-propanol at the same concentration. The samples were sonicated for $2 \mathrm{~min}$ (bath sonicator). Volumes of $1 \mu \mathrm{L}$ of the respective SWCNT dispersion were drop-cast between the gold electrodes until a resistance of $5-20 \mathrm{k} \Omega$ was achieved.

Sensing measurements: The devices were enclosed in a homemade Teflon ${ }^{\mathrm{TM}}$ gas flow chamber for sensing measurement. The low concentration gas mixtures were produced using a KIN-TEK gas generator system[18]. A trace amount of analyte generated by heating the analyte is mixed with a nitrogen stream (oven flow), which can be further diluted with nitrogen (dilution flow). Calibration measurements were performed by placing the analyte in the oven flow for set amounts of time and determined its weight loss.

Electrochemical measurements were performed using a PalmSens handheld potentiostat (PalmSens Instruments) for single device measurements or an EmStat-MUX handheld potentiostat (PalmSens Instruments) for array measurements. A constant bias voltage of $0.1 \mathrm{~V}$ was applied across the device, while current vs. time was measured. During the measurement the volume of gas flow over the device was held constant and switched between nitrogen and analyte/nitrogen.

NMR binding studies: The receptor was dissolved in $\mathrm{CDCl}_{3}$ at a concentration of $0.01 \mathrm{M}$ (for 1-4) or $2.5 \mathrm{mM}$ (for 9) and a ${ }^{1} \mathrm{H}$ NMR spectrum was measured. Subsequently, cyclohexanone 
Submitted to

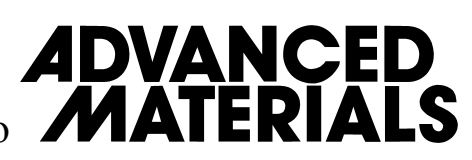

was added to achieve a ratio of cyclohexanone to the receptor of $0.1,0.3,0.5,0.7,0.9,1.0,3.0$, 5.0, 10.0, 15.0, 20.0, 25.0, and 50.0 (for 1-4) and 0.1, 0.3, 0.5, 0.7, 0.8, 1.0, 2.7, 4.4, 8.4, 12.5, 16.6, 20.7, 24.7, 40.4, and 144 (for 9). A ${ }^{1} \mathrm{H}$ NMR spectrum was recorded after every addition and the chemical shifts of the protons were recorded. Using the software package

WinEQNMR2 with the chemical shifts of the NH and aromatic protons (for 1-4) or proton at the 4-position of the $\mathrm{CF}_{3}$-substituted phenyl group in 9 (labeled e' in Fig 2a), association constants were determined.

\section{Acknowledgements}

This work was supported by the Army Research Office through the Institute for Soldier Nanotechnologies (W911NF-07-D-004). Supporting Information is available online from Wiley InterScience or from the author.

Received: ((will be filled in by the editorial staff))

Revised: ((will be filled in by the editorial staff)) Published online: ((will be filled in by the editorial staff))

[1] L. Senesac, T. G. Thundat, Materials Today 2008, 11, 28.

[2] M. Pumera, Electrophoresis 2006, 27, 244.

[3] H. Lai, A. Leung, M. Magee, J. R. Almirall, Anal. Bioanal. Chem. 2010, 396, 2997.

[4] J. R. Cox, P. Müller, T. M. Swager, J. Am. Chem. Soc. 2011, 133, 12910.

[5] D. R. Kauffman, A. Star, Angew. Chem. Int. Ed. 2008, 47, 6550.

[6] J. M. Schnorr, T. M. Swager, Chem. Mater. 2011, 23, 646.

[7] K. A. Mirica, J. G. Weis, J. M. Schnorr, B. Esser, T. M. Swager, Angew. Chem. Int. Ed. 2012, 51, 10740 .

[8] R. J. Chen, Y. Zhang, D. Wang, H. Dai, J. Am. Chem. Soc. 2001, 123, 3838.

[9] (a) F. Wang, H. Gu, T. M. Swager, J. Am. Chem. Soc. 2008, 130, 5392-5393. (b) F. Wang, Y. Yang, T. M. Swager, Angew. Chem. Int. Ed., 2008, 47, 8394-8396.

[10] (a) F. Wang, T. M. Swager, J. Am. Chem. Soc. 2011, 133, 11181. (b) E. Bekyarova, M. Davis, T. Burch, M. E. Itkis, B. Zhao, S. Sunshine, R. C. Haddon, J. Phys. Chem. B 2004, 108, 19717. 
[11] C. B. Jacobs, M. J. Peairs, B. J. Venton, Anal. Chim. Acta 2010, 662, 105-27.

[12] (a) V. Amendola, L. Fabbrizzi, L. Mosca, Chem. Soc. Rev. 2010, 39, 3889. (b) S. Nishizawa, P. Bühlmann, M. Iwao, Y. Umezawa, Tetrahedron Lett. 1995, 36, 6483.

[13] C. Gao, H. He, L. Zhou, X. Zheng, Y. Zhang, Chem. Mater. 2009, 21, 360.

[14] E. Bekyarova, I. Kalinina, X. Sun, T. Shastry, K. Worsley, X. Chi, M. E. Itkis, R. C. Haddon, Adv. Mater. 2010, 22, 848.

[15] B. P. Hay, Chem. Soc. Rev. 2010, 39, 3700.

[16] S. J. Brooks, P. a Gale, M. E. Light, Chem. Commun. 2005, 4696.

[17] Mechanical Damage Caused the High Noise Level of One Pristine SWCNT Device. Therefore, Only the Other Pristine SWCNT Device Was Used for Further Analysis.

[18] B. Esser, J. M. Schnorr, T. M. Swager, Angew. Chem. Int. Ed. 2012, 5752-5756.

\section{Figures:}

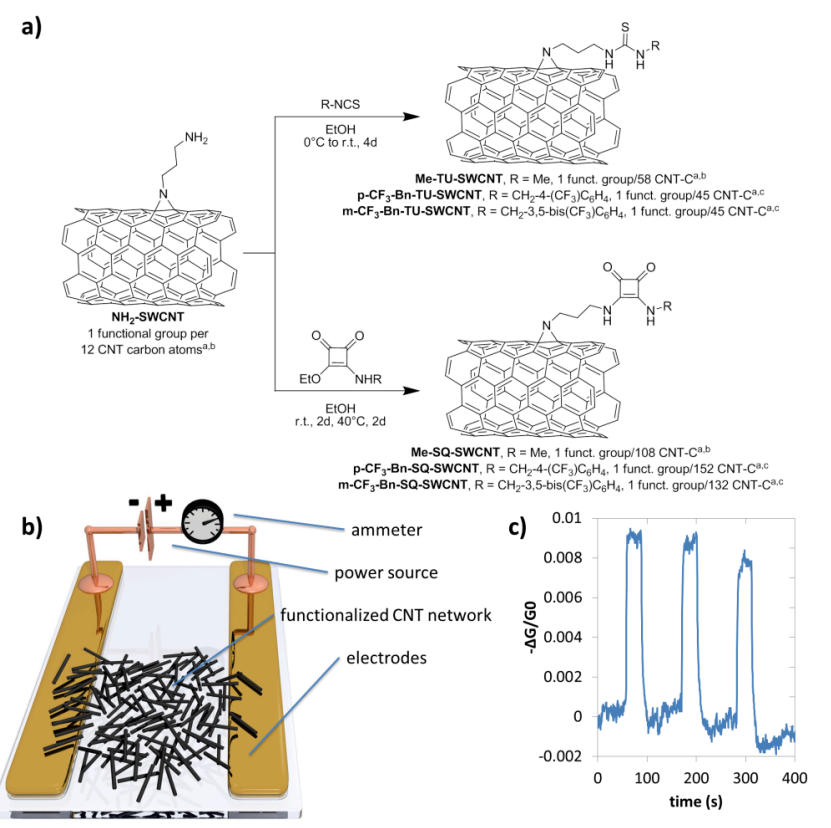

Figure 1. (a) Functionalization of SWCNTs with selectors. ${ }^{\text {a}}$ Functional group density is determined by X-ray photoelectron spectroscopy. ${ }^{\mathrm{b}}$ Based on $\mathrm{O} 1 \mathrm{~s}$ and $\mathrm{C} 1 \mathrm{~s}$ signals in the product compared to $\mathrm{NH}_{2}-\mathrm{SWCNT}$; ${ }^{\mathrm{c}}$ Based on $\mathrm{F}$ 1s and $\mathrm{C} 1 \mathrm{~s}$ signals (b) Schematic representation of resistivity-based SWCNT gas sensor. (c) Response of sensor based on $\mathbf{m}$ $\mathbf{C F}_{3}$-Bn-TU-SWCNT to 57 ppm cyclohexanone. 

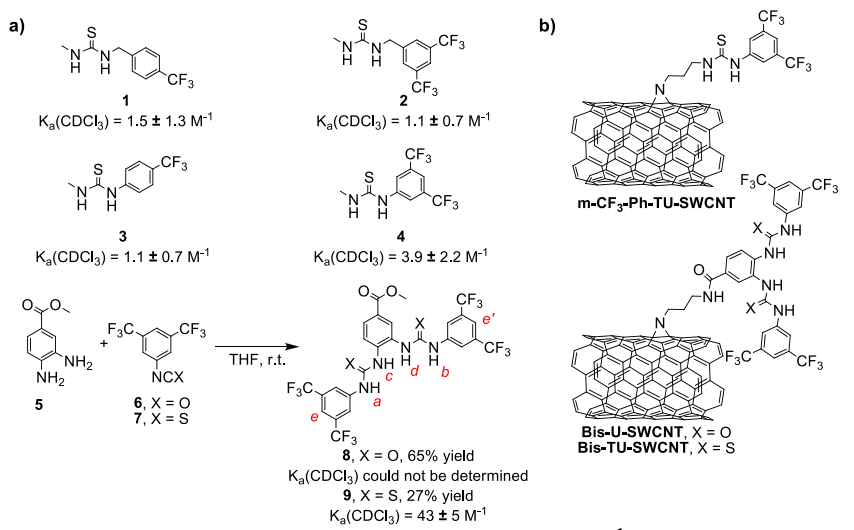

Submitted to

Figure 2. (a) Model compounds for ${ }^{1} \mathrm{H}$ NMR binding study with cyclohexanone. Association constants and errors of 1-4 are based on shifts of two aromatic and two NH protons; association constant and error of 9 is based on proton e. (b) Functionalized SWCNTs with selectors based on ${ }^{1} \mathrm{H}$ NMR binding study.

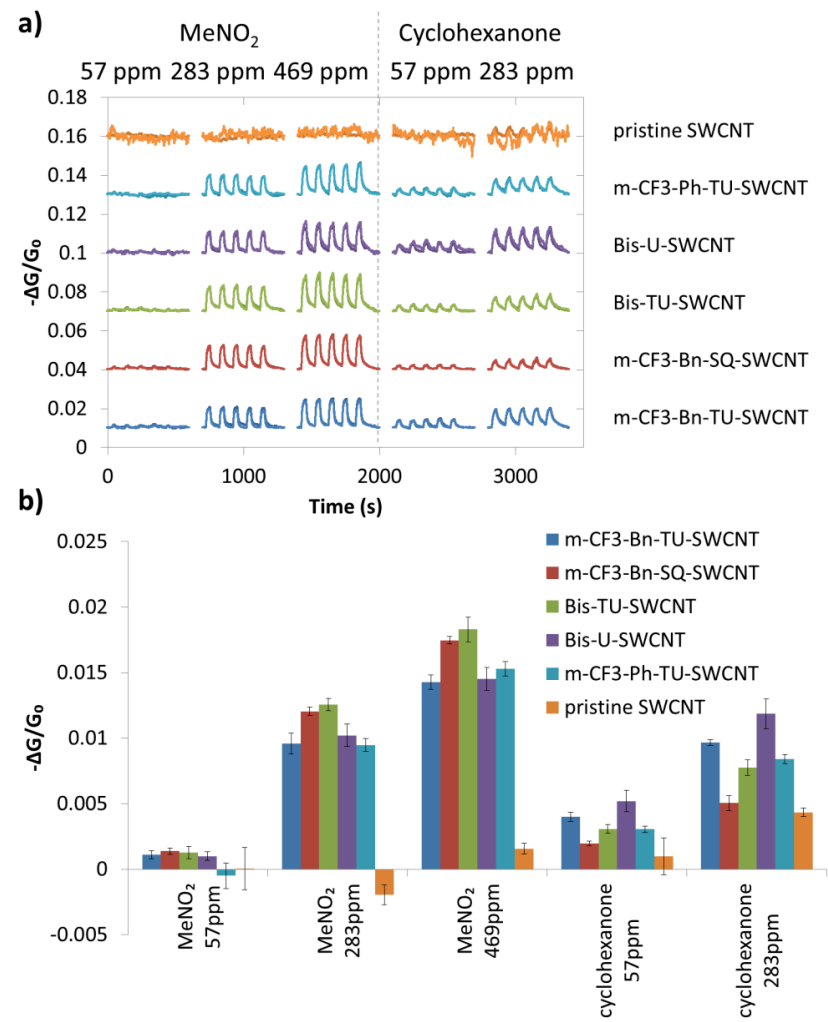

Figure 3. (a) Sensing response of an array of SWCNT devices to nitromethane and cyclohexanone vapor at different concentrations. Data from two different sensors with the same type of functionalized SWCNTs are overlaid on each line. The traces appear in most cases as a single trace as a result of the excellent sensor to sensor reproducibility. (b) Average sensing response and standard deviation over 4 peaks and two devices for each analyte and type of SWCNT. One pristine SWCNT device displayed an unusually high noise level and was therefore omitted to calculate the values for pristine SWCNT sensors. 
Submitted to

a)
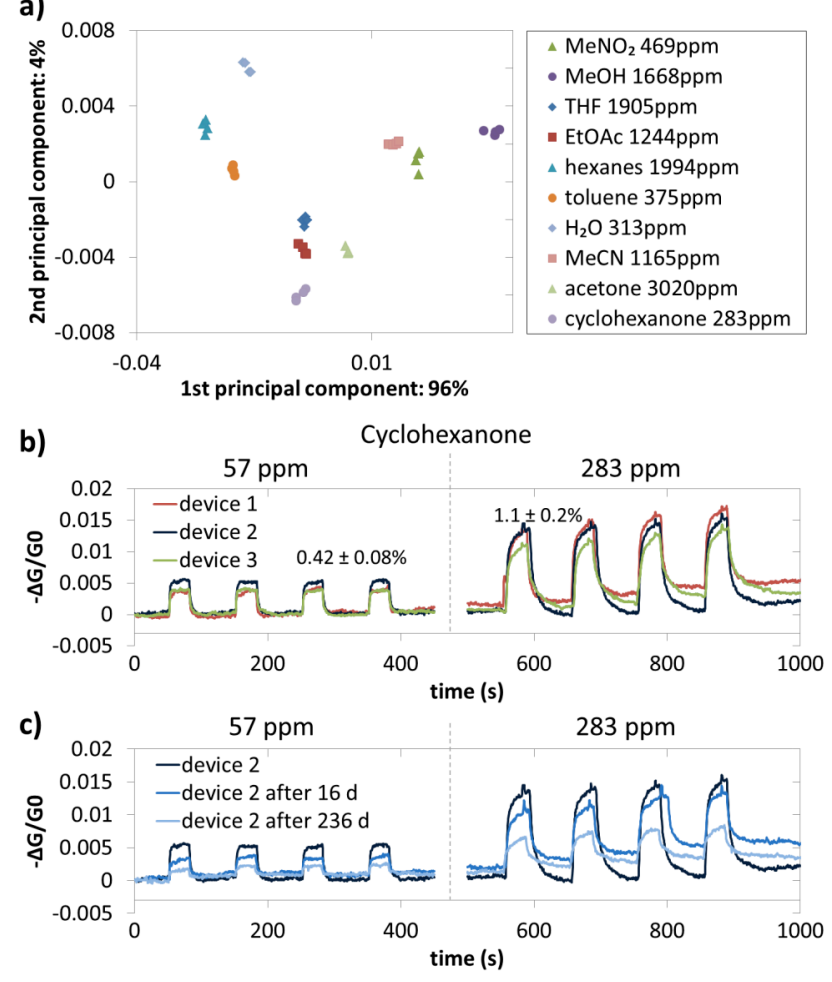

Figure 4. (a) Principal component analysis of sensing response to different analytes using two sensors each based on Bis-U-SWCNT, Bis-TU-SWCNT, m-CF - Ph-TU-SWCNT, m-CF $\mathbf{3}_{\mathbf{3}}$ Bn-TU-SWCNT, and $\mathbf{m}-\mathbf{C F}_{\mathbf{3}}-\mathbf{B n}-\mathbf{S Q}-\mathbf{S W C N T}$. (b) Sensing response of three different devices prepared with $\mathbf{m}-\mathbf{C F}_{\mathbf{3}}-\mathbf{B n}-\mathbf{T U}-\mathbf{S W C N T}$ to $57 \mathrm{ppm}$ and $283 \mathrm{ppm}$ cyclohexanone. Averages and errors are based on four measurements per analyte concentration and all three devices. (c) sensing response of one device prepared with $\mathbf{m}-\mathbf{C F}_{\mathbf{3}}-\mathbf{B n}-\mathbf{T U}-\mathbf{S W C N T}$ to $57 \mathrm{ppm}$ and $283 \mathrm{ppm}$ cyclohexanone, directly after device fabrication, after 16 days and after 236 days of storage under ambient conditions without additional precautions. 
The table of contents entry

Sensor arrays for cyclohexanone and nitromethane are fabricated using single-walled carbon nanotubes (SWCNTs) that are covalently functionalized with different types of selector units. The thiourea, urea and squaramide-based selectors are optimized for improved sensing response. The sensors can be easily fabricated and integrated into electronic circuits.

Furthermore, they show a very high level of reproducibility and promising long-term stability.

sensors, explosive detection, carbon nanotubes, thiourea

Jan M. Schnorr, Daan van der Zwaag, Joseph J. Walish, Yossef Weizmann, and Timothy M. Swager*

Sensory Arrays of Covalently Functionalized Single-Walled Carbon Nanotubes for Explosive Detection

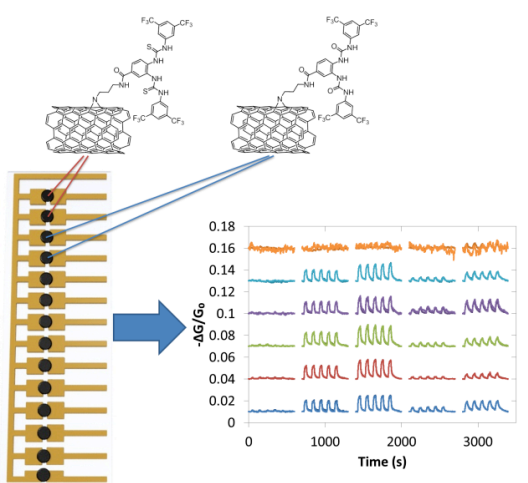




\section{Submitted to \\ ADANECES
MAATRRALIS}

Supporting Information

\section{Materials}

SWCNTs were received from SouthWest NanoTechnologies (CG-100,>90\% carbon content, lot \# CG100-000-0012) and used without further purification. All solvents were of spectroscopic grade unless otherwise noted. Unless specified, all chemicals were of reagent grade and used as received.

\section{General Methods and Instrumentation}

XPS spectra were recorded on a Kratos AXIS Ultra X-ray Photoelectron Spectrometer. Optical micrographs were recorded using a Leica DMRXP optical microscope with an attached Sony DXC-970MD camera. Scanning electron microscope (SEM) images were obtained on a JEOL 6700 scanning electron microscope. All synthetic manipulations were carried out under an argon atmosphere using standard Schlenk techniques unless otherwise noted. 


\section{Synthesis}

\section{ADVANCEP
MAAERRALS}

Submitted to
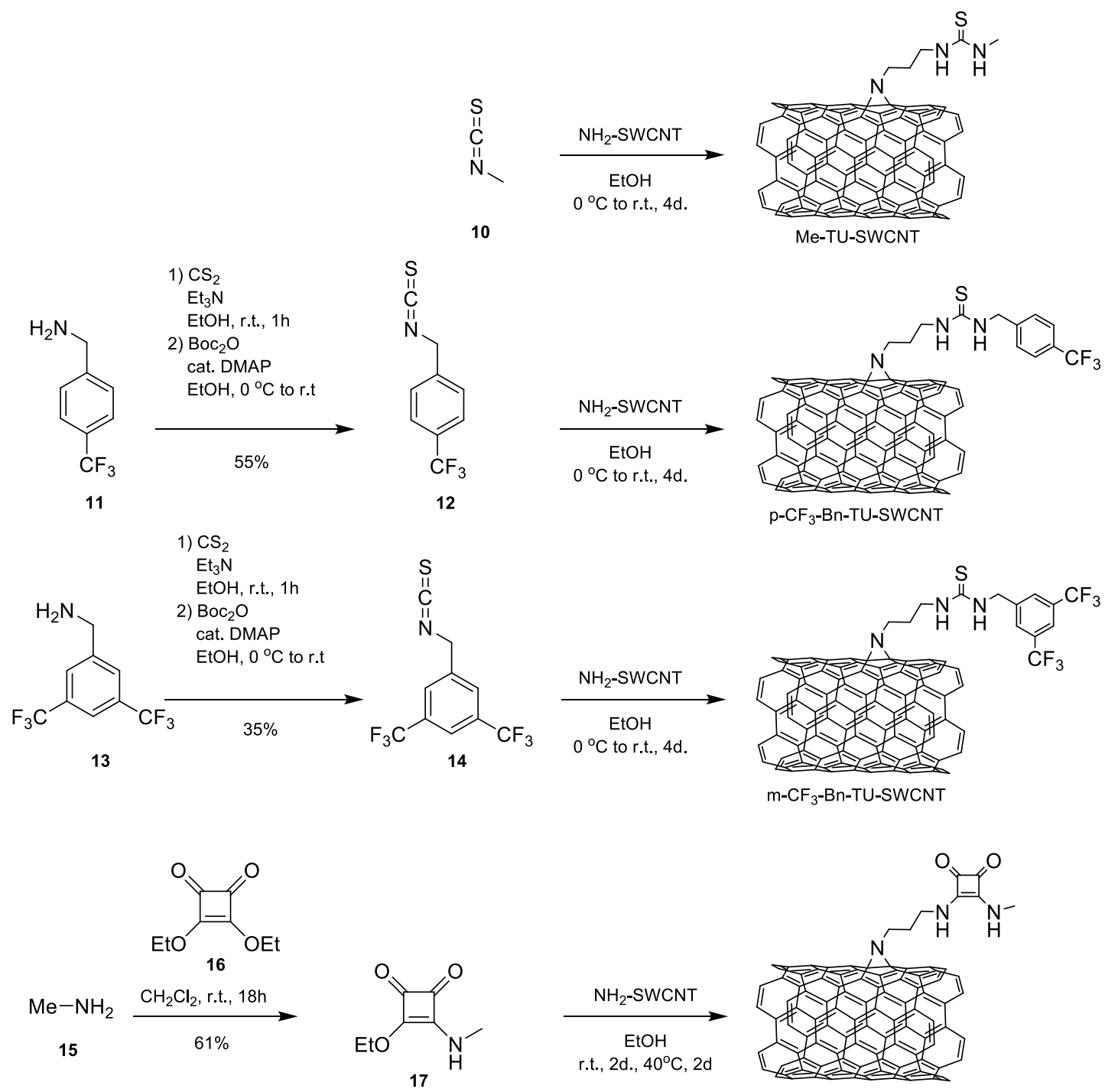<smiles>NCc1ccc(C(F)(F)F)cc1</smiles>

11

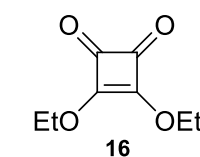

$\underset{44 \%}{\stackrel{\mathrm{CH}_{2} \mathrm{Cl}_{2} \text {, r.t., } 18 \mathrm{~h}}{\longrightarrow} \mathrm{EtO}}$

18
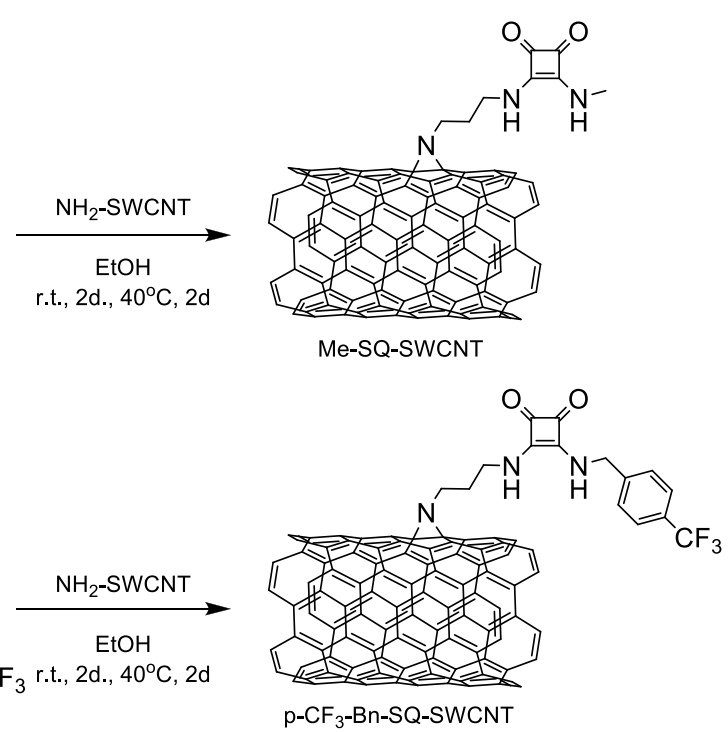<smiles>CCOc1c(OCC)c(=O)c1=O</smiles>

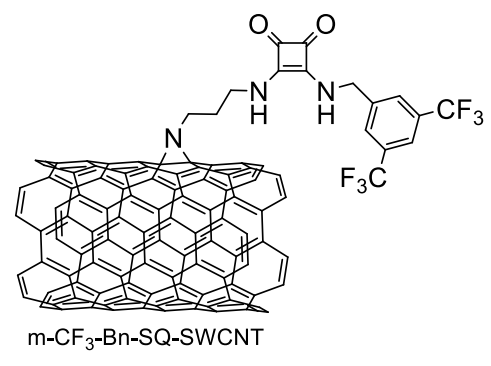

Figure S 1. Synthesis of thiourea and squaramide functionalized SWCNT. 


\section{Submitted to \\ ADVANCED}

3-azidopropan-1-amine. 3-azidopropan-1-amine was synthesized following a literature procedure[13]. Note: Molecules with a high density of azide groups are potentially explosive and particular caution has thus to be used, especially when isolating azides[19,20]. Before synthesizing the compound on the described scale the molecule was prepared on small scale and the explosive hazard has been evaluated (shock, heat). $65.6 \mathrm{~g}$ (0.3 mol) 3bromopropylamine hydrobromide were dissolved in $200 \mathrm{~mL} \mathrm{H}_{2} \mathrm{O}$ and added to $39.0 \mathrm{~g}$ (2 equiv) sodium azide in $160 \mathrm{~mL} \mathrm{H}_{2} \mathrm{O}$. The mixture was refluxed for $15 \mathrm{~h}$ and subsequently cooled in an ice bath. Afterward, it was poured into $400 \mathrm{~mL}$ diethyl ether containing $24 \mathrm{~g}$ $\mathrm{NaOH}$ ( 2 equiv). The organic phase was separated and the aqueous phase was extracted twice with $100 \mathrm{~mL} \mathrm{Et}_{2} \mathrm{O}$. The combined organic phases were dried over $\mathrm{MgSO}_{4}$, filtered and stored in solution. A small aliquot was concentrated for characterization by NMR. The concentration in solution was determined by ${ }^{1} \mathrm{H}-\mathrm{NMR}$ to be $0.3 \mathrm{M}$ using toluene as an internal standard. Yield: $470 \mathrm{~mL}$ of $0.3 \mathrm{M}$ solution (47\%). ${ }^{1} \mathrm{H}-\mathrm{NMR}\left(\mathrm{CDCl}_{3}, 400 \mathrm{MHz}\right): \delta=3.33(\mathrm{t}, 2 \mathrm{H}, J=6.6$ $\mathrm{Hz}$ ); $2.76\left(\mathrm{t}, 2 \mathrm{H}, J=7.0 \mathrm{~Hz}\right.$ ); 1.68 (quin, $2 \mathrm{H}, J=6.8 \mathrm{~Hz}$ ); 1.17 (s, broad, $2 \mathrm{H}$ ). ${ }^{13} \mathrm{C}-\mathrm{NMR}$ $\left(\mathrm{CDCl}_{3}, 100 \mathrm{MHz}\right): \delta=49.2,39.4,32.6$.

1-(isothiocyanatomethyl)-4-(trifluoromethyl)benzene 12. $11(0.81 \mathrm{~g}, 4.60 \mathrm{mmol})$ was dissolved in $5 \mathrm{~mL}$ absolute EtOH. While stirring, $\mathrm{CS}_{2}(3.50 \mathrm{~g}, 46.0 \mathrm{mmol})$ and $\mathrm{Et}_{3} \mathrm{~N}(0.47 \mathrm{~g}$, $4.60 \mathrm{mmol}$ ) were added. After stirring for $60 \mathrm{~min}$., the solution was cooled on an ice bath, precipitating dithiocarbamate. Once cooled, a solution of $\mathrm{Boc}_{2} \mathrm{O}(0.98 \mathrm{~g}, 4.50 \mathrm{mmol})$ in $1 \mathrm{~mL}$ absolute EtOH and a solution of DMAP $(17 \mathrm{mg}, 0.14 \mathrm{mmol})$ in $1 \mathrm{~mL}$ absolute EtOH were added. After stirring at $0{ }^{\circ} \mathrm{C}$ for 5 minutes, the reaction mixture was warmed to r.t. The mixture was stirred until evolution of gas had completed and was then concentrated. The product was purified by flash silica chromatography (DCM, gradient to $2 \% \mathrm{MeOH}$ ) elutes product first. Yield: $0.544 \mathrm{~g}(2.51 \mathrm{mmol}, 55 \%) .{ }^{1} \mathrm{H}-\mathrm{NMR}\left(400 \mathrm{MHz}, \mathrm{CDCl}_{3}\right): \delta 7.63(\mathrm{~d}, 2 \mathrm{H}, J$ $=8.0 \mathrm{~Hz}), 7.42(\mathrm{~d}, 2 \mathrm{H}, J=8.4 \mathrm{~Hz}), 4.77(\mathrm{~s}, 2 \mathrm{H}) .{ }^{13} \mathrm{C}-\mathrm{NMR}(100 \mathrm{MHz}, \mathrm{CDCl} 3): \delta 138.4(\mathrm{~s})$, 134.0 (s broad), 130.9 (q, $J=32.5 \mathrm{~Hz}), 127.3$ (s), 126.2 (q, $J=3.8 \mathrm{~Hz}), 124.0$ (q, $J=270.5$ $\mathrm{Hz}), 48.4$ (s).

1-(isothiocyanatomethyl)-3,5-bis(trifluoromethyl)benzene 14. 14 was prepared from 13 following the same procedure as described for 12.: $0.461 \mathrm{~g}$ (1.62 mmol, 35\%). ${ }^{1} \mathrm{H}-\mathrm{NMR}$ (400 $\mathrm{MHz}_{\mathrm{CDCl}}$ ): $\delta 7.84(\mathrm{~s}, 1 \mathrm{H}), 7.76(\mathrm{~s}, 2 \mathrm{H}), 4.87$ (s, 2H). ${ }^{13} \mathrm{C}-\mathrm{NMR}\left(100 \mathrm{MHz}, \mathrm{CDCl}_{3}\right): \delta$ 137.2 (s), 136.1 (s broad), 132.7 (q, $J=33.5 \mathrm{~Hz}), 127.2$ (q, $J=3.7 \mathrm{~Hz}), 123.1$ (q, $J=271.2$ $\mathrm{Hz}), 122.6$ (m), 48.1 (s).

3-ethoxy-4-(methylamino)cyclobut-3-ene-1,2-dione 17. 16 (0.57 g, $3.34 \mathrm{mmol})$ was dissolved in $15 \mathrm{~mL}$ DCM in water-free conditions. A solution of 15 in THF (1.78 mL, 2.0 M) was added while stirring under Ar atmosphere. After stirring for 18, the mixture was filtered, and the filtrate was washed with $35 \mathrm{~mL} 1 \mathrm{~N} \mathrm{HCl}(\mathrm{aq})$. The organic layer was dried with $\mathrm{Na}_{2} \mathrm{SO}_{4}$, filtered and concentrated. The product was isolated by flash silica chromatography (DCM to elute diethylsquarate, then DCM/MeOH 98:2). Yield: $0.315 \mathrm{~g}$ (2.03 mmol, 61\%). The ${ }^{1} \mathrm{H}-\mathrm{NMR}$ spectrum shows 2 full sets of peaks, due to a high rotation barrier around the C- 
Submitted to

$\mathrm{N}$ bond (ratio isomer 1 to isomer 2: 3.8). ${ }^{1} \mathrm{H}-\mathrm{NMR}\left(400 \mathrm{MHz}, \mathrm{CDCl}_{3}\right.$ ): Isomer 1: $\delta 7.31$ (s broad, $1 \mathrm{H}), 4.65(\mathrm{q}, 2 \mathrm{H}, J=6.8 \mathrm{~Hz}), 3.06(\mathrm{~d}, 3 \mathrm{H}, J=4.8 \mathrm{~Hz}), 1.35(\mathrm{t}, 3 \mathrm{H}, J=6.8 \mathrm{~Hz})$. Isomer 2: $\delta 6.66$ (s broad, $1 \mathrm{H}), 4.57$ (q broad, $2 \mathrm{H}, J=6.8 \mathrm{~Hz}$ ), 3.19 (s broad, $3 \mathrm{H}), 1.30$ (t broad, $3 \mathrm{H})$. ${ }^{13} \mathrm{C}-\mathrm{NMR}$ (100 MHz, CDCl3): $\delta$ 189.8, 182.8, 177.8, 173.4, 69.8, 31.4, 16.0. HRMS calc. for $\mathrm{C}_{7} \mathrm{H}_{10} \mathrm{NO}_{3}[\mathrm{M}+\mathrm{H}]^{+}: 156.0655$, found: 156.0669 . $[\mathrm{M}+\mathrm{H}]^{+}$

3-ethoxy-4-((4-(trifluoromethyl)benzyl)amino)cyclobut-3-ene-1,2-dione 18. 16 (0.57 g, $3.34 \mathrm{mmol})$ was dissolved in $15 \mathrm{~mL}$ DCM in water-free conditions, and a solution of $11(0.61$ g, $3.51 \mathrm{mmol}$ ) in $3.5 \mathrm{~mL}$ DCM was added while stirring. After stirring for $18 \mathrm{~h}$, the mixture was filtered, and the filtrate was washed with $35 \mathrm{~mL} 1 \mathrm{~N} \mathrm{HCl} \mathrm{(aq).} \mathrm{The} \mathrm{organic} \mathrm{layer} \mathrm{was}$ dried with $\mathrm{Na}_{2} \mathrm{SO}_{4}$, filtered and concentrated. The product was isolated by flash silica chromatography (DCM to elute diethylsquarate, then DCM/MeOH 98:2). Yield: $0.506 \mathrm{~g}$ (1.48 mmol, 44\%). Two isomers were obtained (ratio isomer 1 to isomer 2: 3.3). ${ }^{1} \mathrm{H}-\mathrm{NMR}$ (400 $\mathrm{MHz}, \mathrm{CDCl}_{3}$ ): Isomer 1: $\delta 7.94$ (s broad, $\left.1 \mathrm{H}\right), 7.54$ (d, 2H, $\left.J=7.6 \mathrm{~Hz}\right), 7.39$ (d, 2H, $J=7.6$ Hz), 4.69 (d, 1H, $J=6.4 \mathrm{~Hz}), 4.65$ (s broad, 2H), 4.61 (d, 1H, $J=5.2 \mathrm{~Hz}), 1.36$ (t, 3H, $J=6.4$ Hz). Isomer 2: 7.54 (d, 2H, $J=7.6 \mathrm{~Hz}$ ), 7.39 (d, 2H, $J=7.6 \mathrm{~Hz}$ ), 6.93 (s broad, 1H), 4.82 (s broad, 2H), 4.69 (d, 1H, $J=6.4 \mathrm{~Hz}), 4.61(\mathrm{~d}, 1 \mathrm{H}, J=5.2 \mathrm{~Hz}), 1.36(\mathrm{t}, 3 \mathrm{H}, J=6.4 \mathrm{~Hz}) .{ }^{13} \mathrm{C}-$ NMR (100 MHz, CDCl3): $\delta 189.7$ (s), 183.0 (s), 178.1 (s), 172.7 (s), 141.4 (s), 130.4 (q, $J=$ $32.3 \mathrm{~Hz}$ ), 128.1 (s), 126.0 (q, $J=3.7 \mathrm{~Hz}), 124.1$ (q, $J=270.5 \mathrm{~Hz}), 70.2$ (s), 48.1 (s), 15.9 (s). HRMS calc. for $\mathrm{C}_{14} \mathrm{H}_{12} \mathrm{~F}_{3} \mathrm{NO}_{3}[\mathrm{M}+\mathrm{H}]^{+}: 300.0842$, found: 300.0853 . [M+H] ${ }^{+}$

3-((3,5-bis(trifluoromethyl)benzyl)amino)-4-ethoxycyclobut-3-ene-1,2-dione 19. 19 was prepared from 16 and 13 as described for 18 . Yield: $0.320 \mathrm{~g}(0.87 \mathrm{mmol}, 26 \%)$. Two isomers were obtained (ratio isomer 1 to isomer 2: 2.3$)$. ${ }^{1} \mathrm{H}-\mathrm{NMR}\left(400 \mathrm{MHz}, \mathrm{CDCl}_{3}\right.$ ): Isomer 1: $\delta 7.81$ (s, 1H), 7.76 (s, 2H), 7.53 (s broad, 1H), 4.75 (q, 2H, J =7.2 Hz), 4.73 (s broad, 2H) 1.41 (t, $3 \mathrm{H}, J=7.2 \mathrm{~Hz})$. Isomer 2: $\delta 7.81(\mathrm{~s}, 1 \mathrm{H}), 7.76(\mathrm{~s}, 2 \mathrm{H}), 5.91(\mathrm{~s}$ broad, $1 \mathrm{H}), 4.92(\mathrm{~s}$ broad, $2 \mathrm{H})$, 4.75 (q, $2 \mathrm{H}, J=7.2 \mathrm{~Hz}), 1.41$ (t, 3H, $J=7.2 \mathrm{~Hz}) .{ }^{13} \mathrm{C}-\mathrm{NMR}\left(100 \mathrm{MHz}, \mathrm{CDCl}_{3}\right): \delta 189.7$ (s), 182.9 (s), 178.5 (s), 172.5 (s), 140.0 (s), 132.5 (q, $J=33.3 \mathrm{~Hz}$ ), 128.3 (q, $J=2.8 \mathrm{~Hz}), 123.2$ (q, $J=271.1 \mathrm{~Hz}$ ), $122.3(\mathrm{~m}), 70.5(\mathrm{~s}), 47.6(\mathrm{~s}), 15.8(\mathrm{~s})$. HRMS calc. for $\mathrm{C}_{15} \mathrm{H}_{11} \mathrm{~F}_{6} \mathrm{NO}_{3}[\mathrm{M}+\mathrm{H}]^{+}$: 368.0716, found: 368.0729 . [M+H] $]^{+}$

1-methyl-3-(4-(trifluoromethyl)benzyl)thiourea $1.11(175.2 \mathrm{mg}, 1.0 \mathrm{mmol})$ and $10(73.1$ $\mathrm{mg}, 1.0 \mathrm{mmol}$ ) were each dissolved in $10 \mathrm{~mL}$ DCM. The solutions were combined and stirred at r.t. for $48 \mathrm{~h}$. The product was isolated by flash silica chromatography in DCM:MeOH 97:3. Yield: $226.2 \mathrm{mg}$ (0.91 mmol, 91\%). ${ }^{1} \mathrm{H}-\mathrm{NMR}\left(400 \mathrm{MHz}, \mathrm{CDCl}_{3}\right): \delta 7.53$ (d, 2H, $J=8.4 \mathrm{~Hz}$ ), $7.36(\mathrm{~d}, 2 \mathrm{H}, J=8.0 \mathrm{~Hz}), 6.57$ (s broad, 2H), $4.72(\mathrm{~s}, 2 \mathrm{H}), 2.89$ (d, 3H, $J=4.0 \mathrm{~Hz}) .{ }^{13} \mathrm{C}-\mathrm{NMR}$ (100 MHz, CDCl3): $\delta 182.9$ (s broad), 141.9 (s), 130.0 (q, $J=32.3 \mathrm{~Hz}), 127.8$ (s), 125.8 (q, $J$ $=3.8 \mathrm{~Hz}$ ), $124.2(\mathrm{q}, J=270.4 \mathrm{~Hz}), 47.9$ (s), 30.9 (s broad). HRMS calc. for $\mathrm{C}_{10} \mathrm{H}_{11} \mathrm{~F}_{3} \mathrm{~N}_{2} \mathrm{~S}$ $[\mathrm{M}+\mathrm{H}]^{+}: 249.0668$, found: $249.0689 .[\mathrm{M}+\mathrm{H}]^{+}$

1-(3,5-bis(trifluoromethyl)benzyl)-3-methylthiourea $2.13(243.2 \mathrm{mg}, 1.0 \mathrm{mmol})$ and 10 (73.1 $\mathrm{mg}, 1.0 \mathrm{mmol}$ ) were each dissolved in $10 \mathrm{~mL}$ DCM. The solutions were combined and 


\section{Submitted to

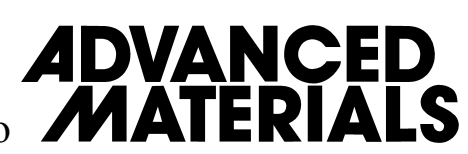

stirred at r.t. for $48 \mathrm{~h}$. The product was isolated by flash silica chromatography in DCM:MeOH 97:3. Yield: $266.4 \mathrm{mg}(0.84 \mathrm{mmol}, 84 \%) .{ }^{1} \mathrm{H}-\mathrm{NMR}\left(400 \mathrm{MHz}, \mathrm{CDCl}_{3}\right): \delta 7.71$ (s, 1H), $7.71(\mathrm{~s}, 2 \mathrm{H}), 6.72$ (s broad, 2H), $4.83(\mathrm{~d}, 2 \mathrm{H}, J=1.2 \mathrm{~Hz}), 2.88(\mathrm{~d}, 3 \mathrm{H}, J=1.2 \mathrm{~Hz})$. ${ }^{13} \mathrm{C}-\mathrm{NMR}\left(100 \mathrm{MHz}, \mathrm{CDCl}_{3}\right): \delta 183.2$ (s broad), 140.9 (s), 132.0 (q, $J=33.2 \mathrm{~Hz}$ ), 127.8 (s), $123.3(\mathrm{q}, J=271.1 \mathrm{~Hz}), 121.6(\mathrm{~m}), 47.6(\mathrm{~s}), 30.8$ (s broad). HRMS calc. for $\mathrm{C}_{11} \mathrm{H}_{10} \mathrm{~F}_{6} \mathrm{~N}_{2} \mathrm{~S}$ $[\mathrm{M}+\mathrm{H}]^{+}:$317.0542, found: $317.0543 .[\mathrm{M}+\mathrm{H}]^{+}$

1-methyl-3-(4-(trifluoromethyl)phenyl)thiourea 3. $p$-Trifluoromethylphenylisothiocyanate (203.2 mg, $1.0 \mathrm{mmol}$ ) was dissolved in $10 \mathrm{~mL}$ dry THF. 15 was added as a solution (1 mL 2.0 $\mathrm{M}, 2.0 \mathrm{mmol}$ ) via syringe. The solution was stirred at r.t. for $24 \mathrm{~h}$ and the product was isolated by flash silica chromatography in DCM:MeOH 98:2. Yield: $195.3 \mathrm{mg}(0.83 \mathrm{mmol}, 83 \%) .{ }^{1} \mathrm{H}-$ NMR (400 MHz, $\left.\mathrm{CDCl}_{3}\right): \delta 8.20(\mathrm{~s}$ broad, $1 \mathrm{H}), 7.68(\mathrm{~d}, 2 \mathrm{H}, J=8.4 \mathrm{~Hz}), 7.35(\mathrm{~d}, 2 \mathrm{H}, J=8.0$ $\mathrm{Hz}), 6.20(\mathrm{~s}$ broad, $1 \mathrm{H}), 3.16(\mathrm{~d}, 3 \mathrm{H}, J=4.8 \mathrm{~Hz}) .{ }^{13} \mathrm{C}-\mathrm{NMR}\left(100 \mathrm{MHz}, \mathrm{CDCl}_{3}\right): \delta 181.7(\mathrm{~s}$ broad), 139.9 (s), 128.8 (q, $J=32.8 \mathrm{~Hz}$ ), 127.5 (q, $J=3.8 \mathrm{~Hz}), 124.5$ (s), 123.8 (q, $J=270.6$ $\mathrm{Hz}$ ), 32.4 (s). HRMS calc. for $\mathrm{C}_{9} \mathrm{H}_{9} \mathrm{~F}_{3} \mathrm{~N}_{2} \mathrm{~S}[\mathrm{M}+\mathrm{H}]^{+}: 235.0511$, found: $235.0527 .[\mathrm{M}+\mathrm{H}]^{+}$

1-(3,5-bis(trifluoromethyl)phenyl)-3-methylthiourea $4 . \quad p$-Trifluoromethylphenylisothiocyanate $(271.2 \mathrm{mg}, 1.0 \mathrm{mmol})$ was dissolved in $10 \mathrm{~mL}$ dry THF. 15 was added as a solution ( $1 \mathrm{~mL} 2.0 \mathrm{M}, 2.0 \mathrm{mmol})$ via syringe. The solution was stirred at r.t. for $24 \mathrm{~h}$ and the product was isolated by flash chromatography in DCM:MeOH 98:2. Yield: $196.1 \mathrm{mg}(0.65$ mmol, 65\%). ${ }^{1} \mathrm{H}-\mathrm{NMR}\left(400 \mathrm{MHz}, \mathrm{CDCl}_{3}\right): \delta 8.44$ (s broad, $\left.1 \mathrm{H}\right), 7.76(\mathrm{~s}, 2 \mathrm{H}), 7.69(\mathrm{~s}, 1 \mathrm{H})$, $6.24(\mathrm{~s}$ broad, $1 \mathrm{H}), 3.12(\mathrm{~d}, 3 \mathrm{H}, J=4.8 \mathrm{~Hz}) .{ }^{13} \mathrm{C}-\mathrm{NMR}\left(100 \mathrm{MHz}, \mathrm{CDCl}_{3}\right): \delta 181.8(\mathrm{~s}$ broad), 138.9 (s), 133.3 (q, $J=34.0 \mathrm{~Hz}$ ), 124.6 (s), 122.9 (q, $J=271.4 \mathrm{~Hz}), 120.0$ (m), 32.2 (s). HRMS calc. for $\mathrm{C}_{10} \mathrm{H}_{8} \mathrm{~F}_{6} \mathrm{~N}_{2} \mathrm{~S}[\mathrm{M}+\mathrm{H}]^{+}: 303.0385$, found: $303.0370 .[\mathrm{M}+\mathrm{H}]^{+}$

Me-TU-SWCNT. $10 \mathrm{mg} \mathrm{NH}$-SWCNT were sonicated for $15 \mathrm{~min}$ in $8 \mathrm{~mL}$ ethanol. $36.7 \mathrm{mg}$ (0.5 mmol) 10 in $3 \mathrm{~mL}$ ethanol were added dropwise at $0{ }^{\circ} \mathrm{C}$. The mixture was stirred for 48 $\mathrm{h}$. The solid was collected by filtration and the product was washed on a filter with ethanol, $\mathrm{CH}_{2} \mathrm{Cl}_{2}$, methanol, water, methanol, and hexanes and subsequently dried in vacuo. Functional group density based on $\mathrm{O} 1 \mathrm{~s}$ and $\mathrm{C}$ 1s signals by XPS: $58 \mathrm{CNT}$ carbon atoms per functional group.

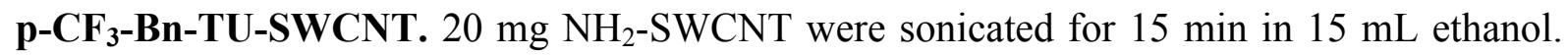
$217 \mathrm{mg}(1.0 \mathrm{mmol}) \mathbf{1 2}$ in $5 \mathrm{~mL}$ ethanol were added dropwise at $0{ }^{\circ} \mathrm{C}$. The mixture was stirred for $48 \mathrm{~h}$. The solid was collected by filtration and the product was washed on a filter with ethanol, $\mathrm{CH}_{2} \mathrm{Cl}_{2}$, methanol, water, methanol, and hexanes and subsequently dried in vacuo. Functional group density based on F 1s and C 1s signals by XPS: 45 CNT carbon atoms per functional group.

Me-SQ-SWCNT. $20 \mathrm{mg} \mathrm{NH}$-SWCNT were sonicated for $15 \mathrm{~min}$ in $15 \mathrm{~mL}$ ethanol. $155 \mathrm{mg}$ (1.0 mmol) 17 in $15 \mathrm{~mL}$ ethanol were added. The mixture was stirred for $48 \mathrm{~h}$ at r.t. and subsequently for $48 \mathrm{~h}$ at $40{ }^{\circ} \mathrm{C}$. The solid was collected by filtration and the product was washed on a filter with ethanol, $\mathrm{CH}_{2} \mathrm{Cl}_{2}$, methanol, water, methanol, and hexanes and 
subsequently dried in vacuo. Functional group density based on $\mathrm{O}$ 1s and $\mathrm{C}$ 1s signals by XPS: 108 CNT carbon atoms per functional group.

p-CF 3 -Bn-SQ-SWCNT. $20 \mathrm{mg} \mathrm{NH}$-SWCNT were sonicated for $15 \mathrm{~min}$ in $15 \mathrm{~mL}$ ethanol. $299 \mathrm{mg}$ ( $1.0 \mathrm{mmol}) \mathbf{1 8}$ in $15 \mathrm{~mL}$ ethanol were added. The mixture was stirred for $48 \mathrm{~h}$ at r.t. and subsequently for $48 \mathrm{~h}$ at $40{ }^{\circ} \mathrm{C}$. The solid was collected by filtration and the product was washed on a filter with ethanol, $\mathrm{CH}_{2} \mathrm{Cl}_{2}$, methanol, water, methanol, and hexanes and subsequently dried in vacuo. Functional group density based on $\mathrm{F} 1 \mathrm{~s}$ and $\mathrm{C} 1 \mathrm{~s}$ signals by XPS: 152 CNT carbon atoms per functional group.

\section{Device preparation}

a)

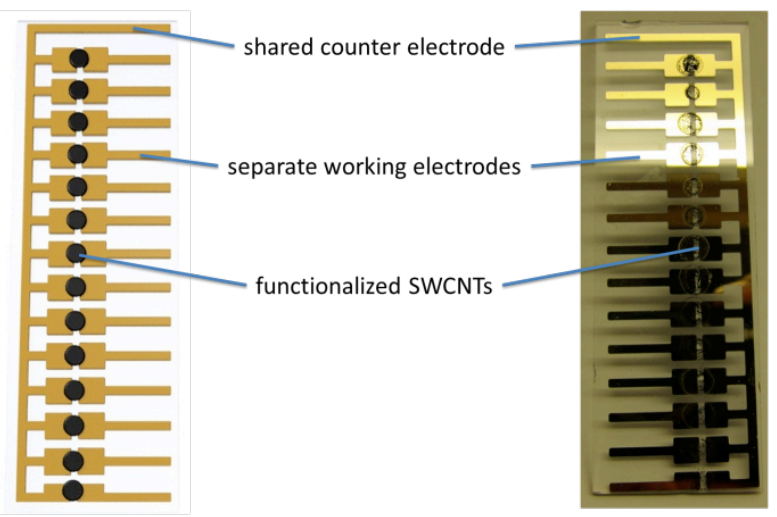

b)

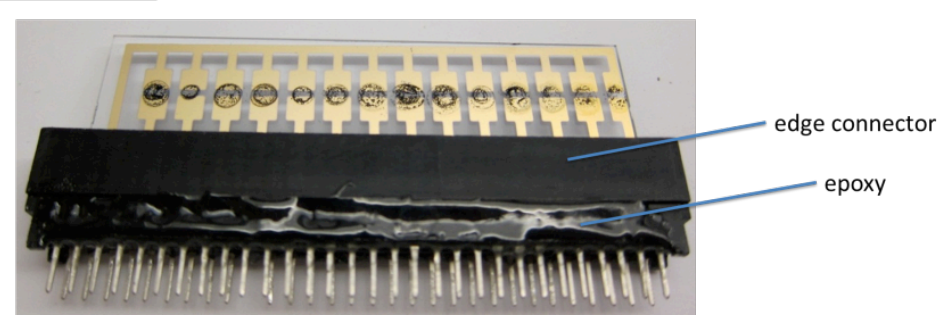

Figure S 2. Devices for array measurements. (a) Schematic drawing and photograph of 14 devices on a glass slide; (b) photograph of glass slide with 14 devices contacted via an edge connector. Openings in the edge connector were covered with epoxy to provide a gas tight seal.

\section{Optical microscopy and SEM analysis of devices}

Devices were analyzed by optical microscopy and scanning electron microscopy (SEM). Optical microscopy showed an inhomogeneous structure of the SWCNT film containing large aggregates of CNTs (Figure S 3a). SEM confirmed this film structure at low magnification (Figure S 3b) and showed SWCNT bundles at higher magnification (Figure S 3c-f). 


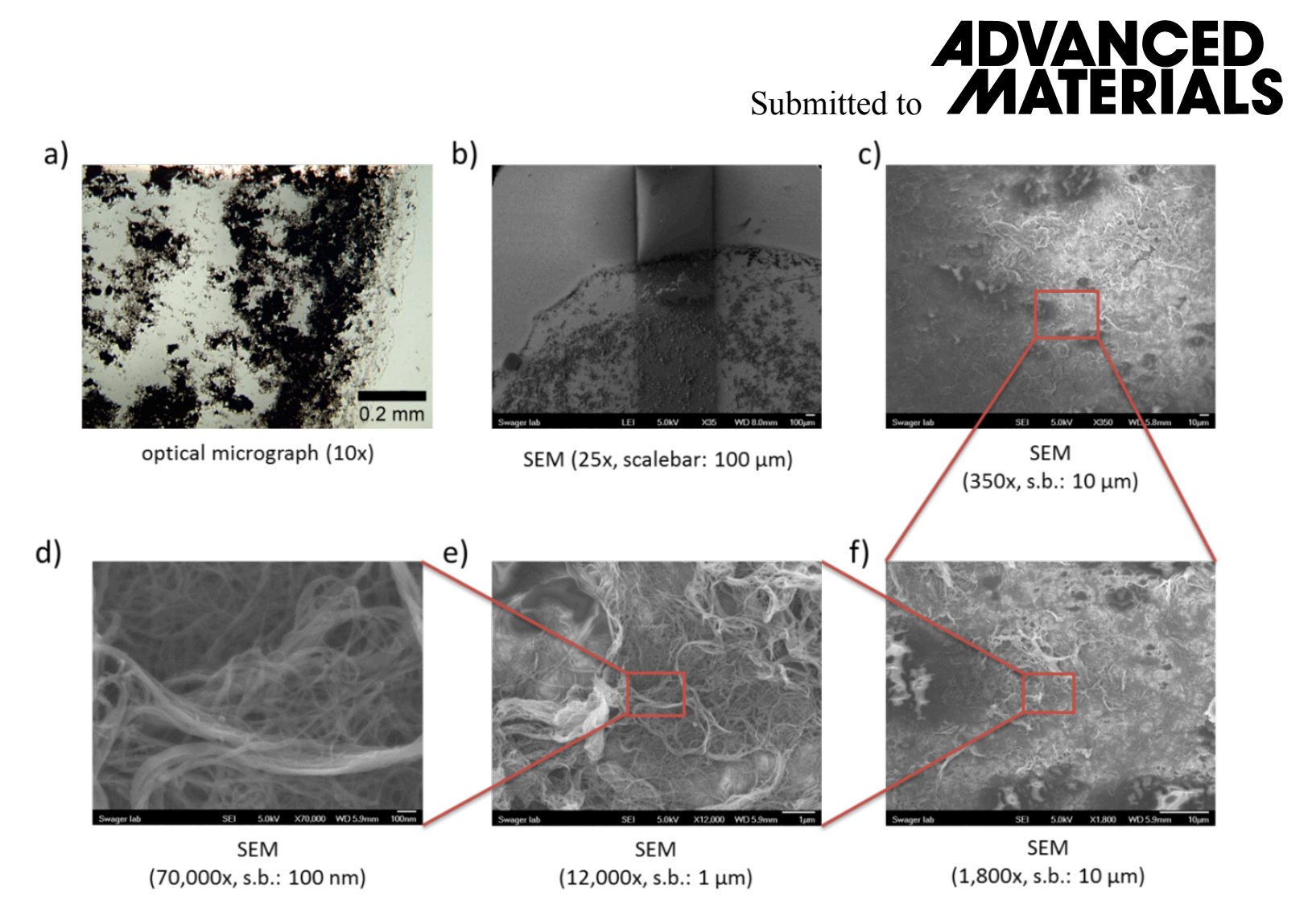

Figure S 3. Micrographs of SWCNT devices. (a) Optical micrograph; (b)-(f) scanning electron micrographs at different magnifications.

\section{Initial sensing results}

Devices were exposed to $57 \mathrm{ppm}$ cyclohexanone in an experiment as described above. Sensing traces are displayed in Figure S 4. The best performance of ca. $0.9 \%$ current change upon exposure to the analyte was achieved using devices based on $\mathbf{m}-\mathbf{C F}_{\mathbf{3}}-\mathbf{B n}-\mathbf{T U}-\mathbf{S W C N T}$. 


\section{Submitted to
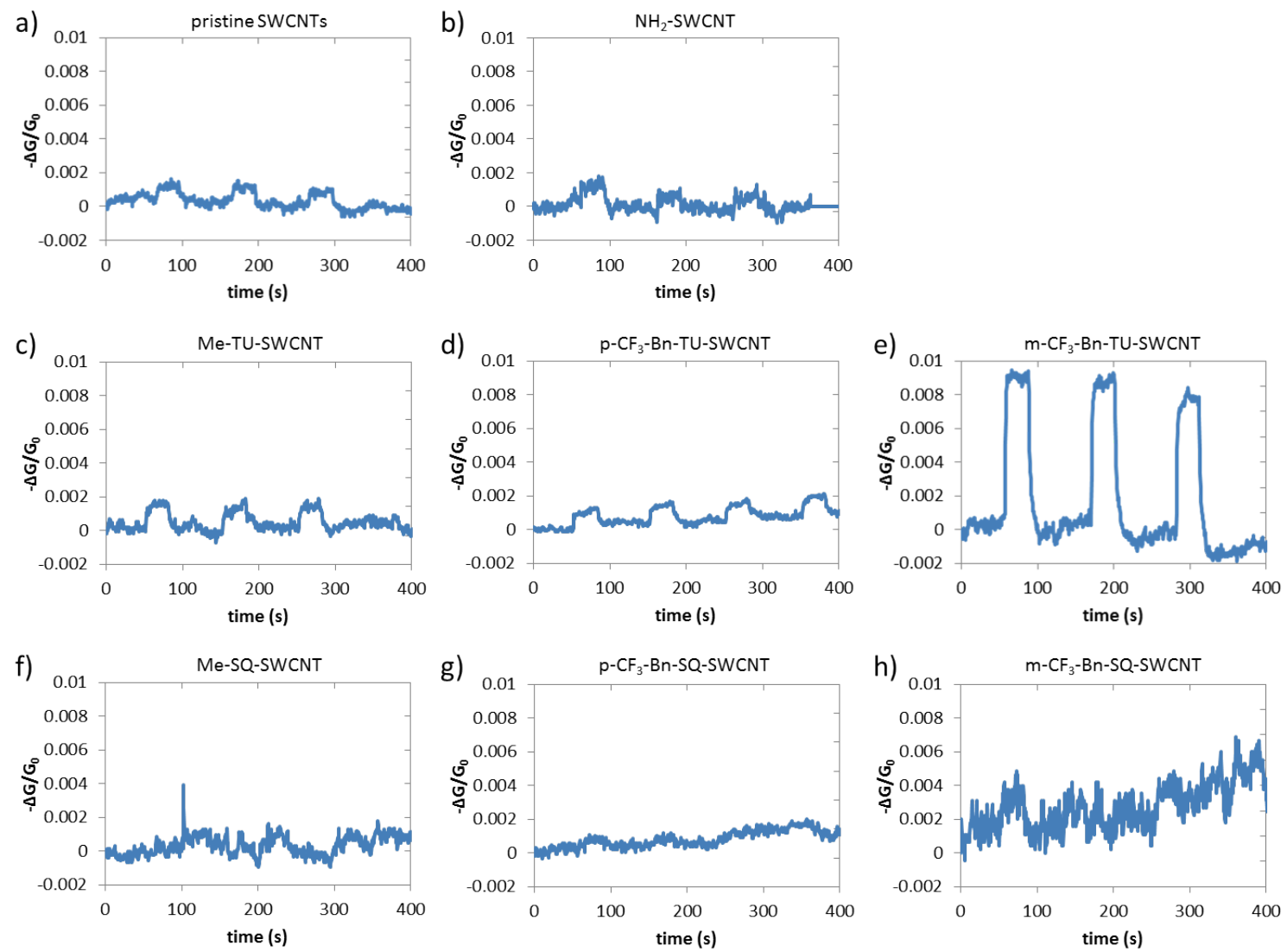

Figure S 4. Sensing responses of devices with different types of SWCNTs to $57 \mathrm{ppm}$ cyclohexanone, applied for $30 \mathrm{~s}$ starting at 50, 150, and $250 \mathrm{~s}$.

\section{NMR binding studies}




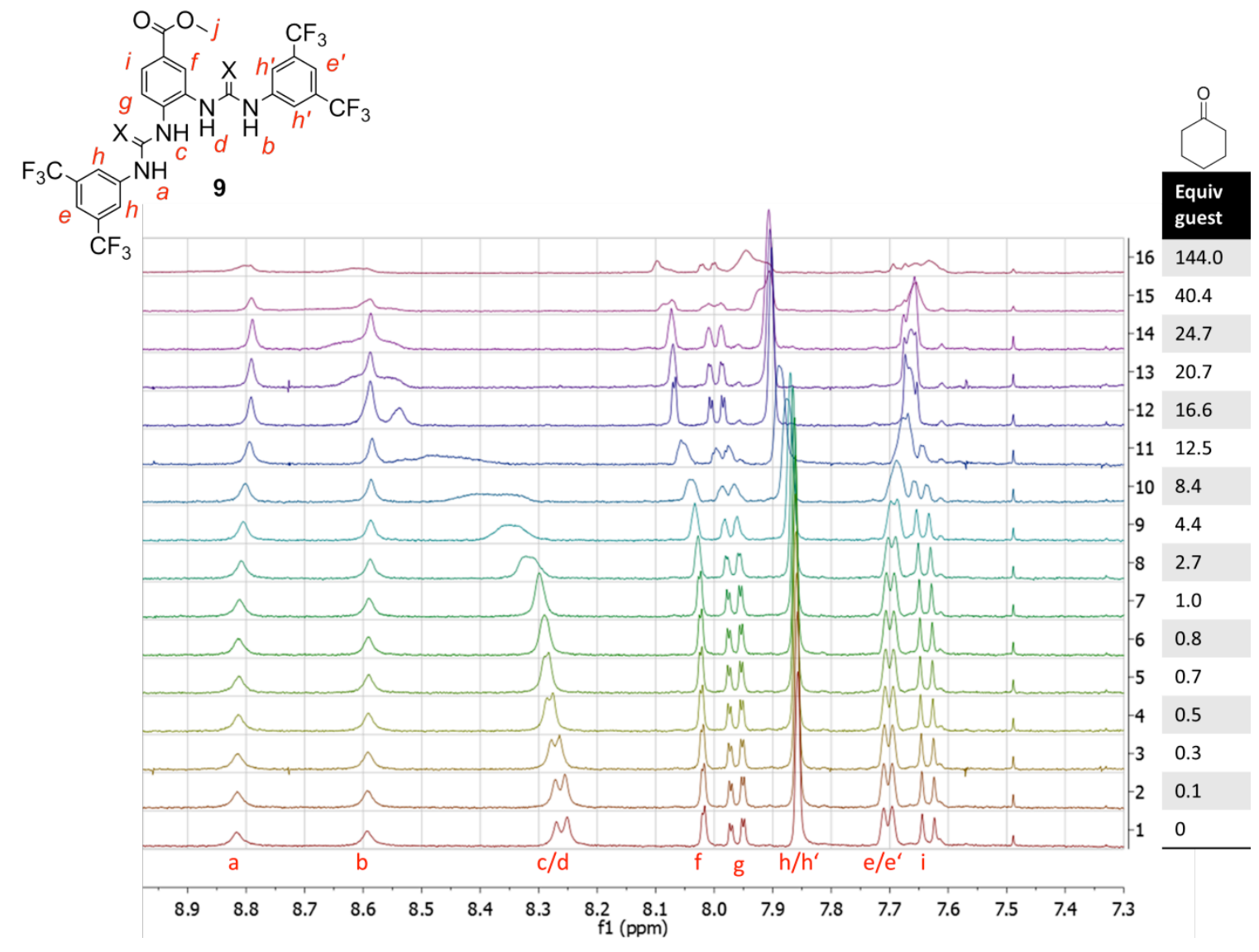

Figure S 5. NMR binding study of 9 and cyclohexanone in $\mathrm{CDCl}_{3}$. 


\section{Submitted to

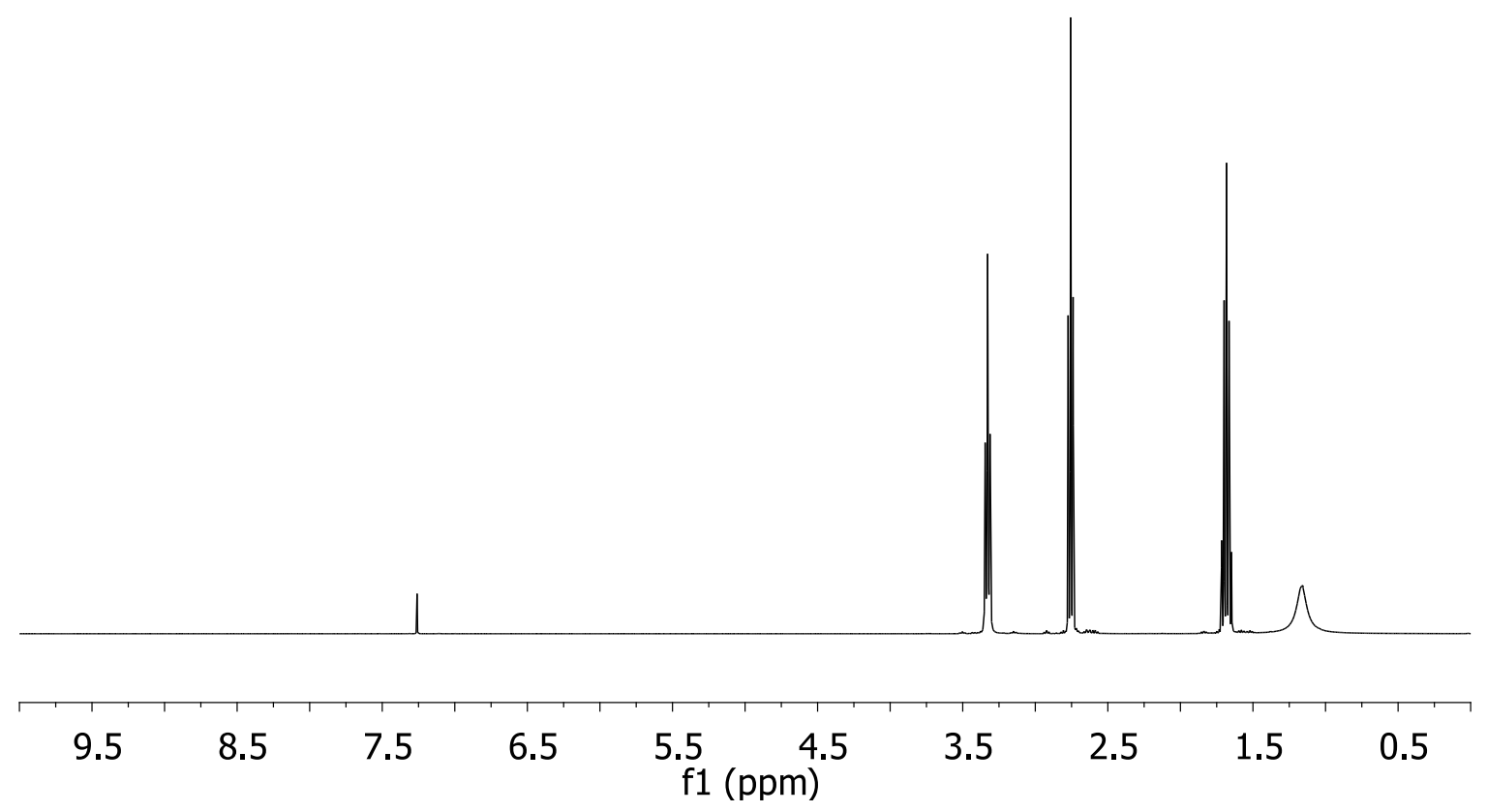

Figure S 6. ${ }^{1} \mathrm{H}$ NMR Spectrum of 3-azidopropan-1-amine $\left(\mathrm{CDCl}_{3}\right)$

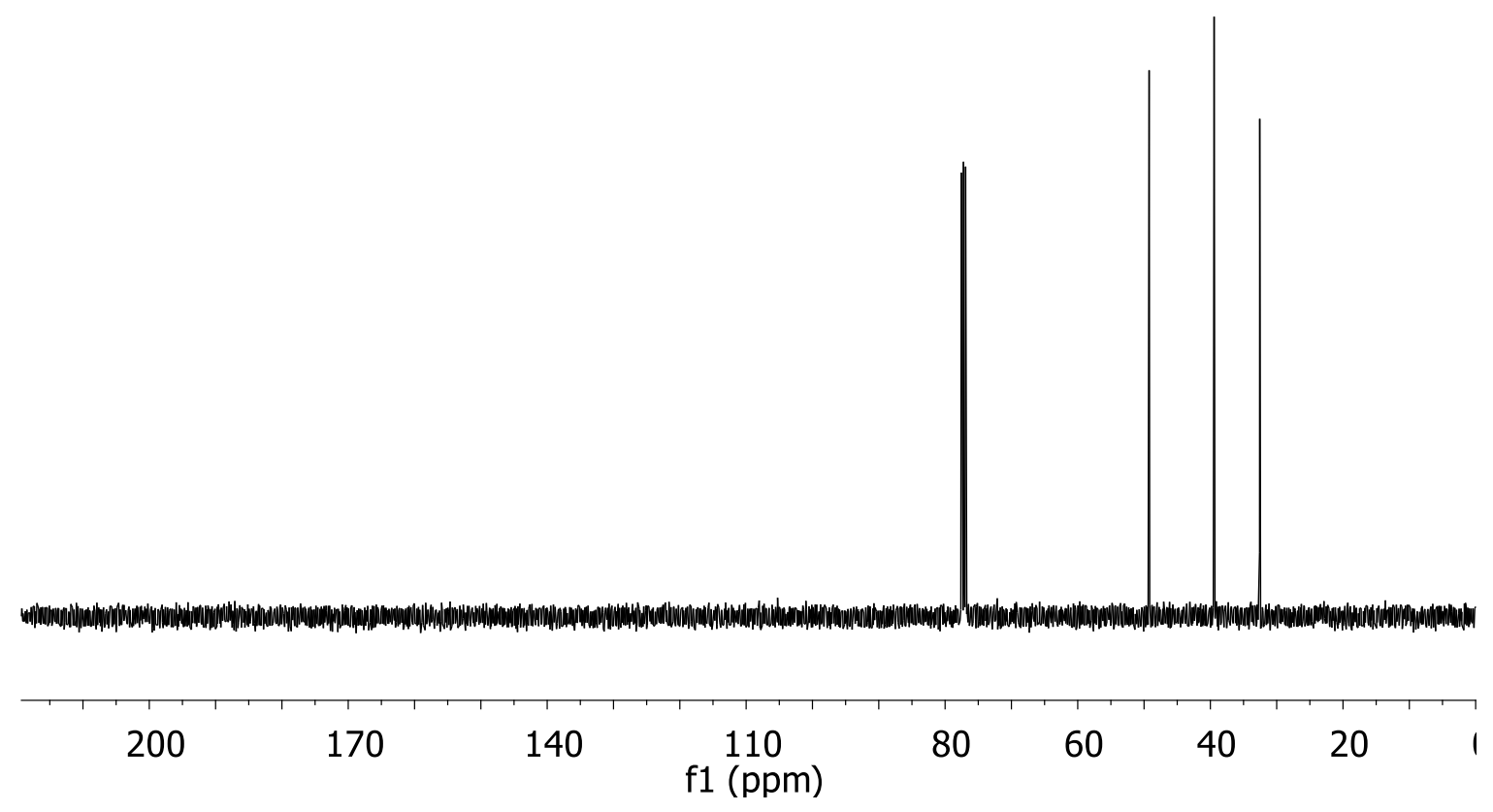

Figure S 7. ${ }^{13} \mathrm{C}$ NMR Spectrum of 3-azidopropan-1-amine $\left(\mathrm{CDCl}_{3}\right)$ 


\section{Submitted to

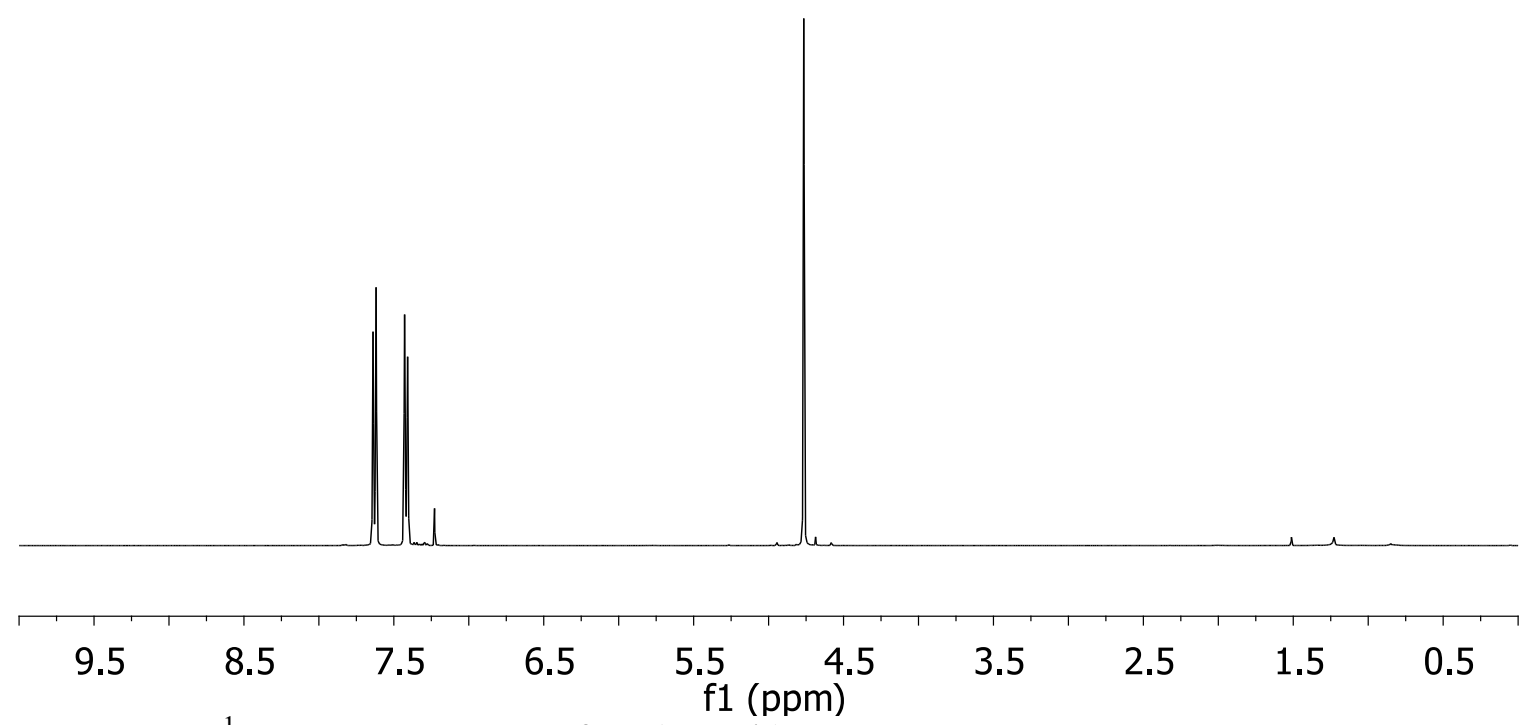

Figure S 8. ${ }^{1} \mathrm{H}$ NMR Spectrum of $12\left(\mathrm{CDCl}_{3}\right)$

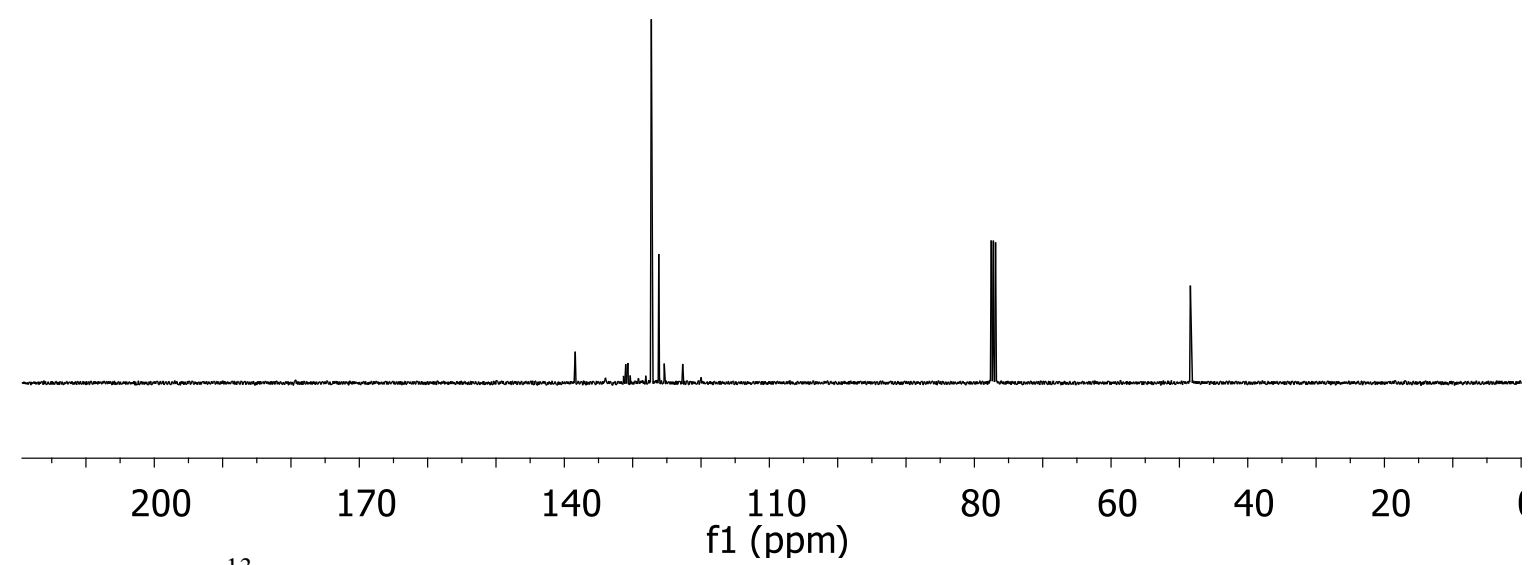

Figure S 9. ${ }^{13} \mathrm{C}$ NMR Spectrum of $12\left(\mathrm{CDCl}_{3}\right)$ 


\section{Submitted to

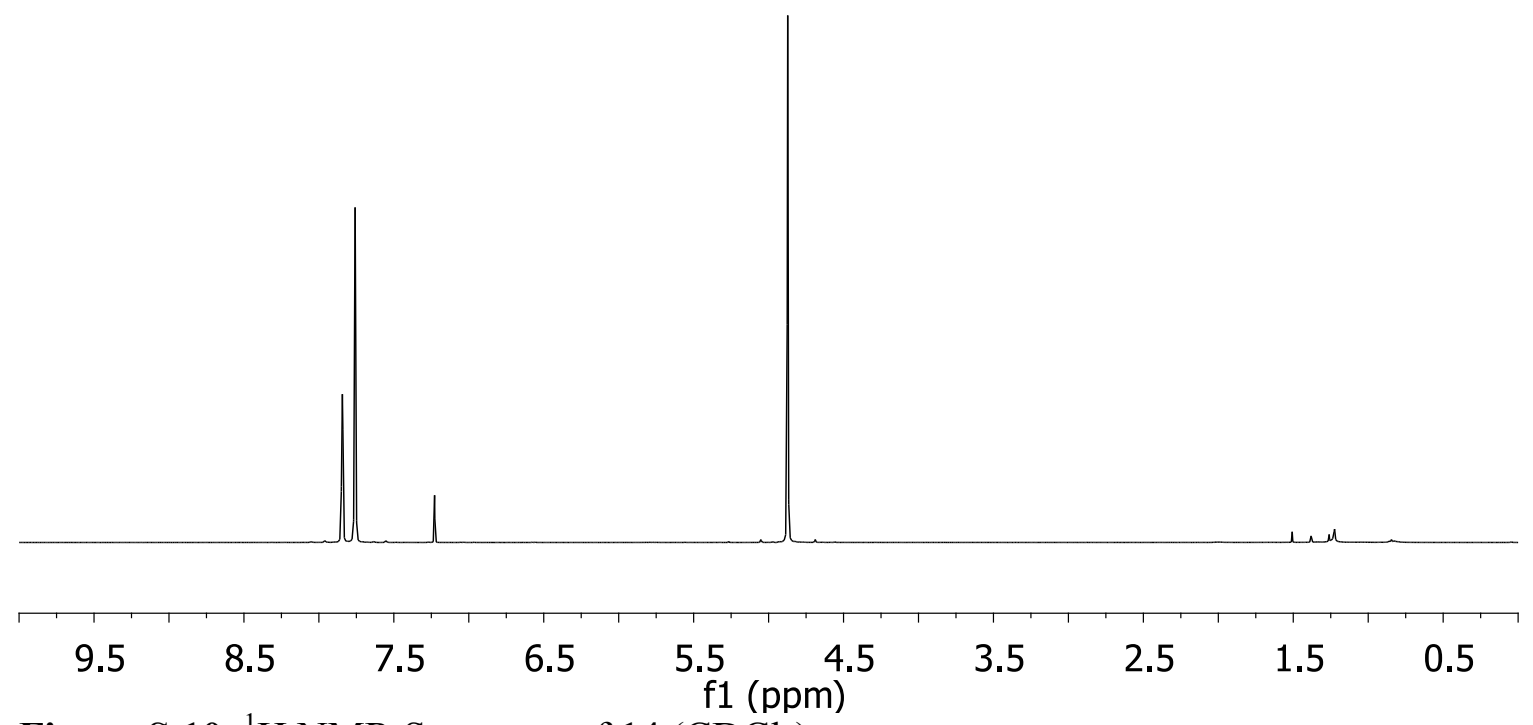

Figure S 10. ${ }^{1} \mathrm{H}$ NMR Spectrum of $14\left(\mathrm{CDCl}_{3}\right)$

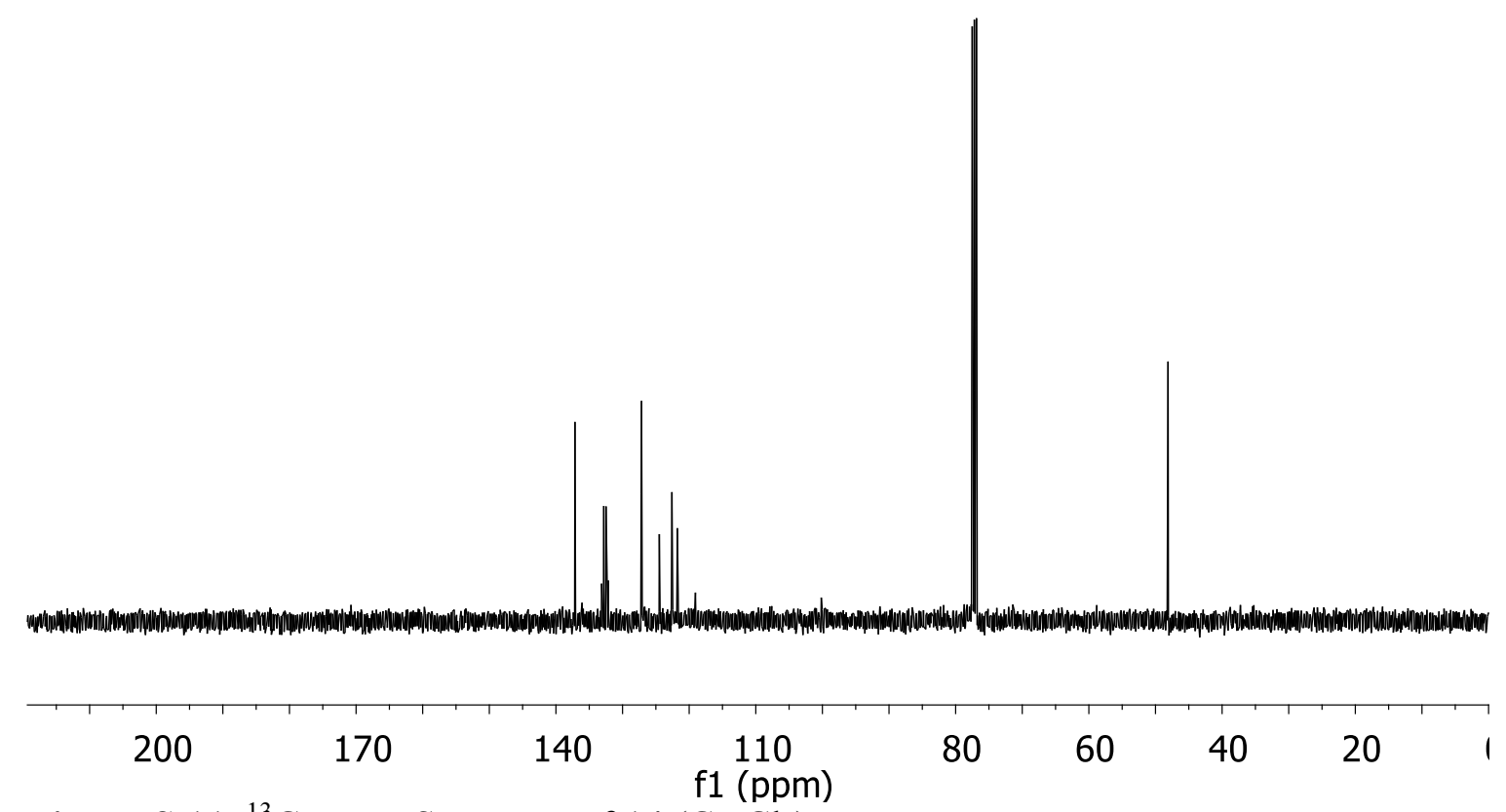

Figure S 11. ${ }^{13} \mathrm{C}$ NMR Spectrum of $14\left(\mathrm{CDCl}_{3}\right)$ 


\section{ADNANCEPS
MAAERRALS \\ Submitted to}

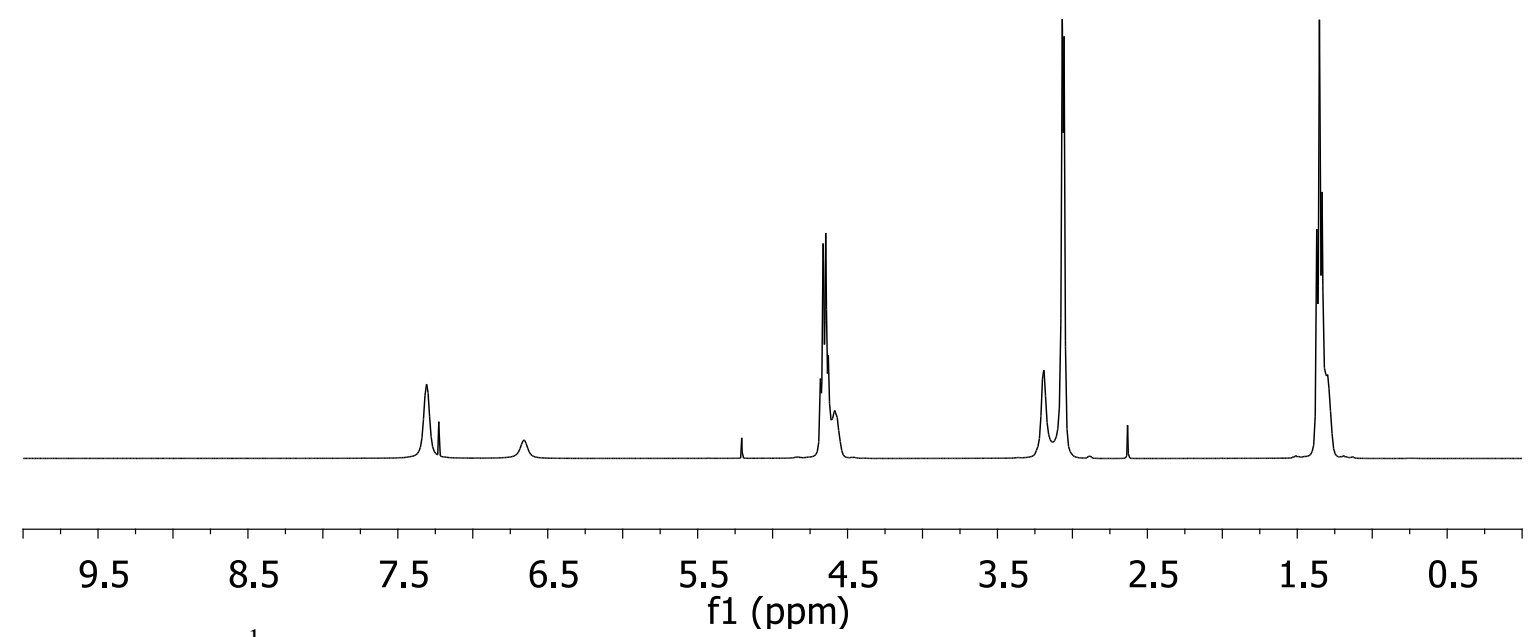

Figure S 12. ${ }^{1} \mathrm{H}$ NMR Spectrum of $17\left(\mathrm{CDCl}_{3}\right)$

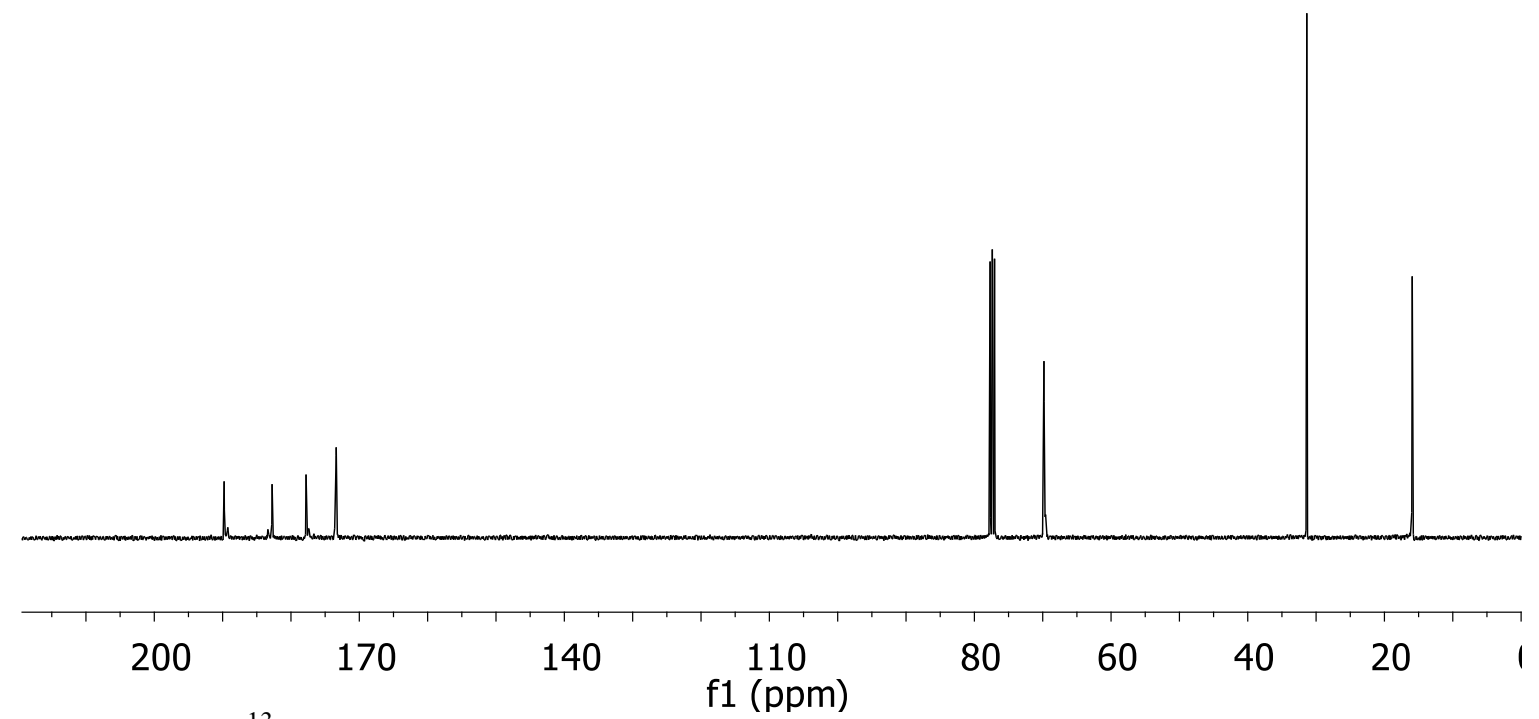

Figure S 13. ${ }^{13} \mathrm{C}$ NMR Spectrum of $17\left(\mathrm{CDCl}_{3}\right)$ 


\section{Submitted to

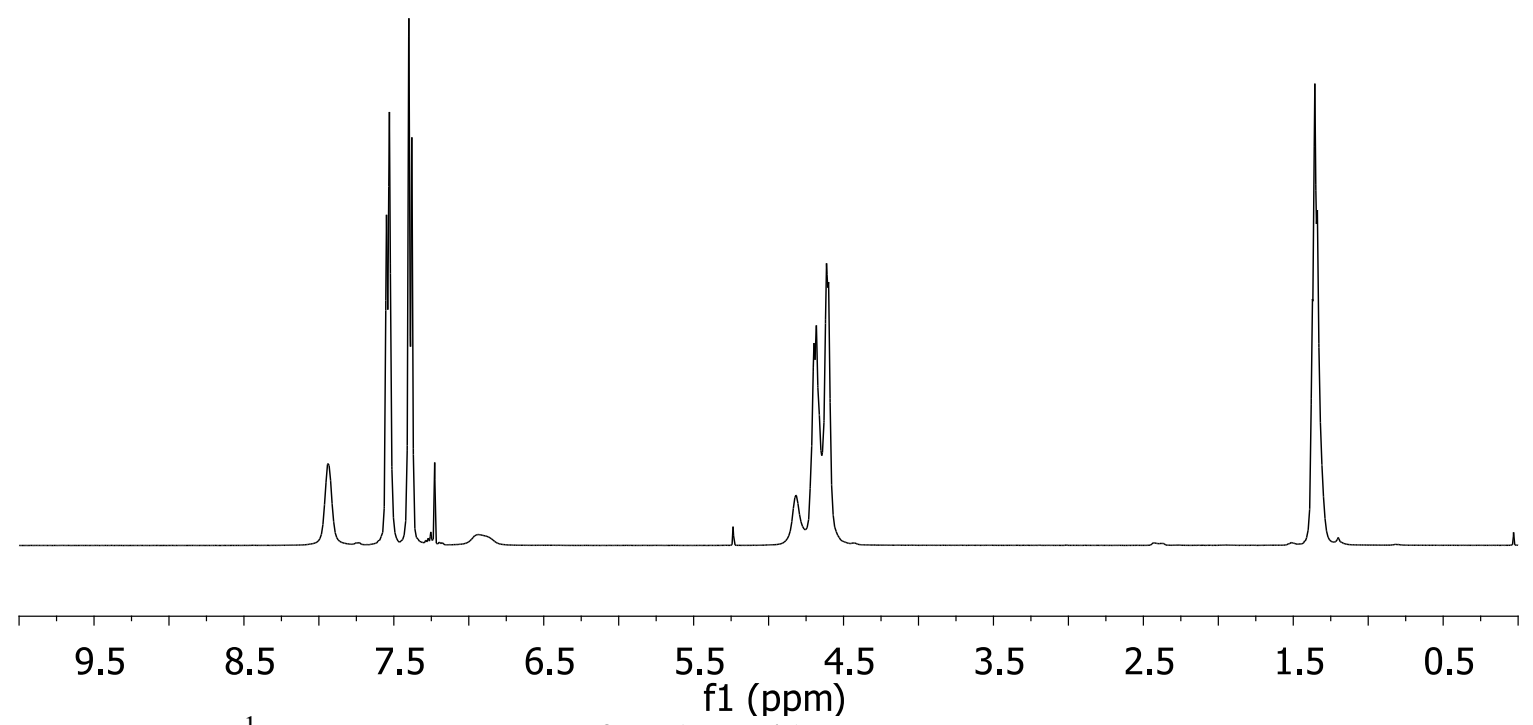

Figure S 14. ${ }^{1} \mathrm{H}$ NMR Spectrum of $18\left(\mathrm{CDCl}_{3}\right)$

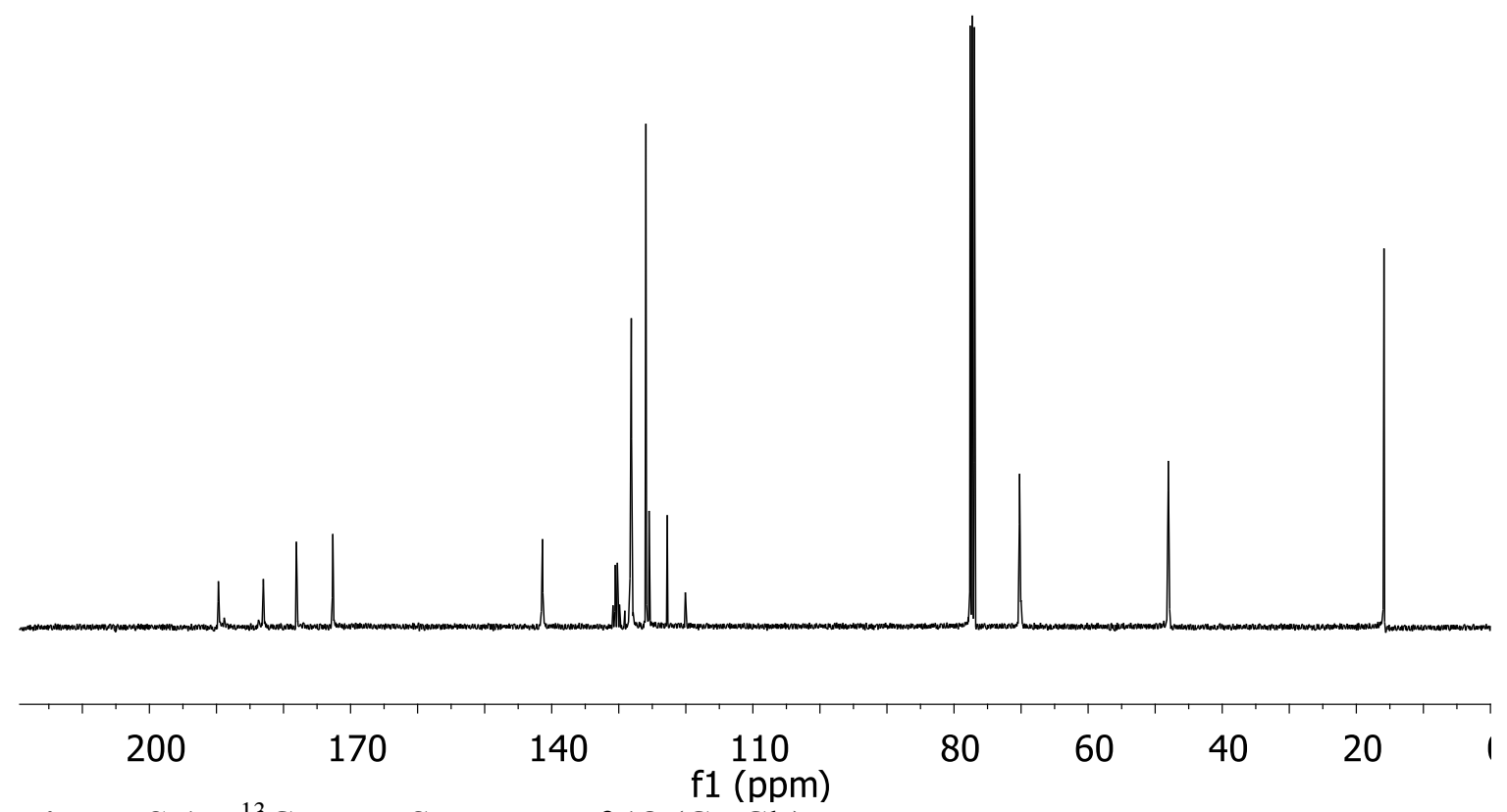

Figure S 15. ${ }^{13} \mathrm{C}$ NMR Spectrum of $18\left(\mathrm{CDCl}_{3}\right)$ 


\section{Submitted to

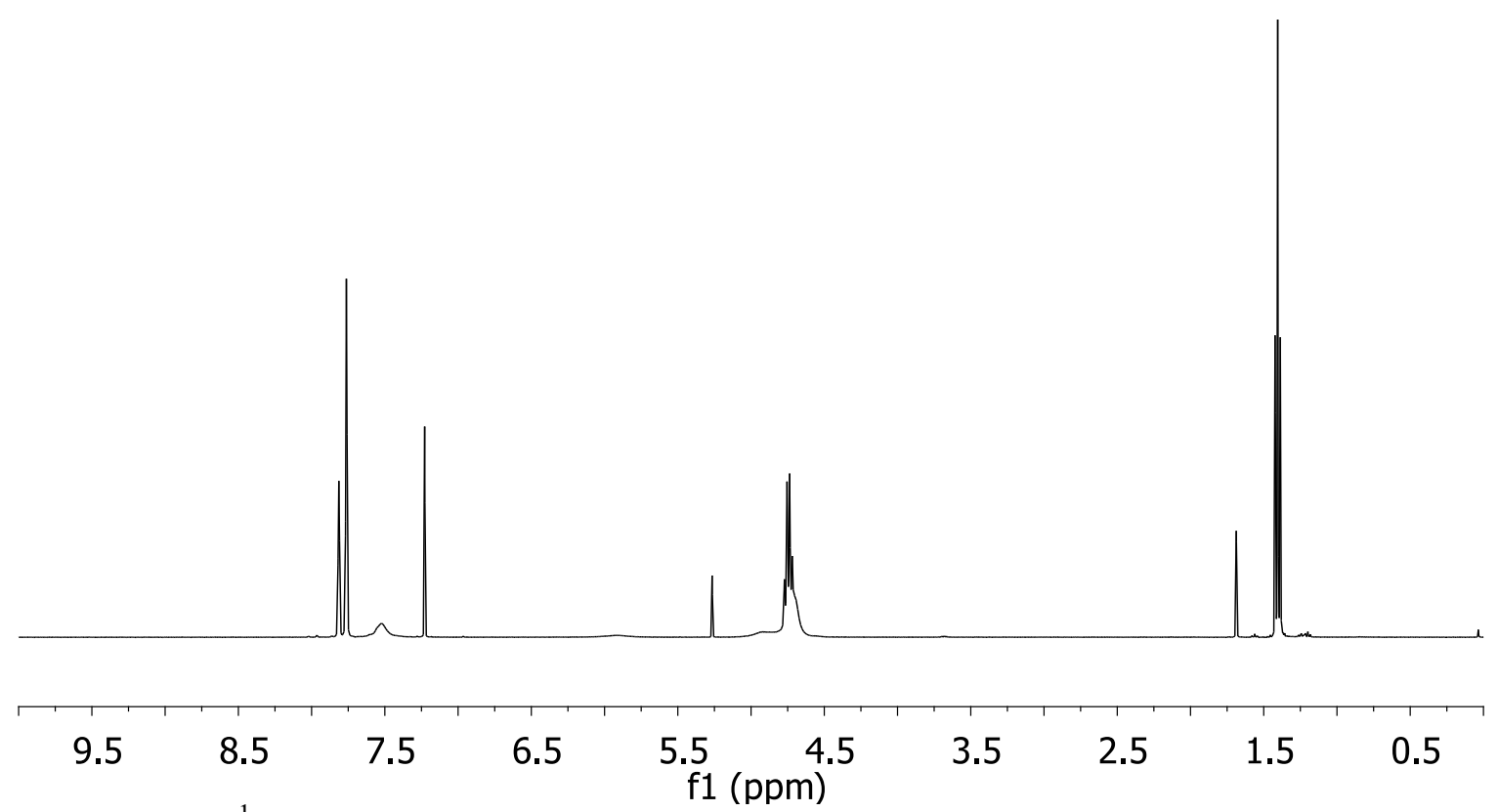

Figure S 16. ${ }^{1} \mathrm{H}$ NMR Spectrum of $19\left(\mathrm{CDCl}_{3}\right)$

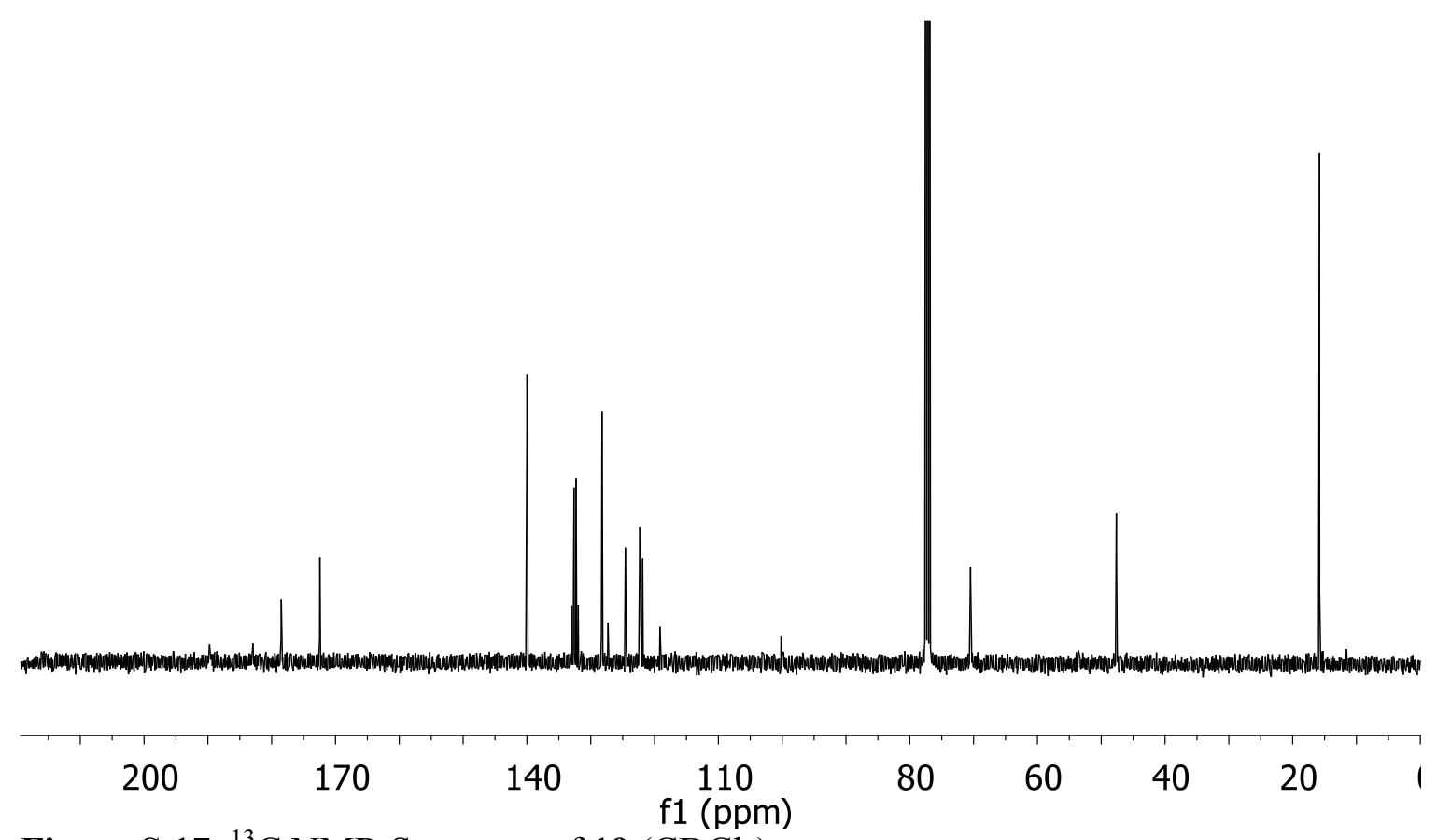

Figure S 17. ${ }^{13} \mathrm{C}$ NMR Spectrum of $19\left(\mathrm{CDCl}_{3}\right)$ 


\section{Submitted to

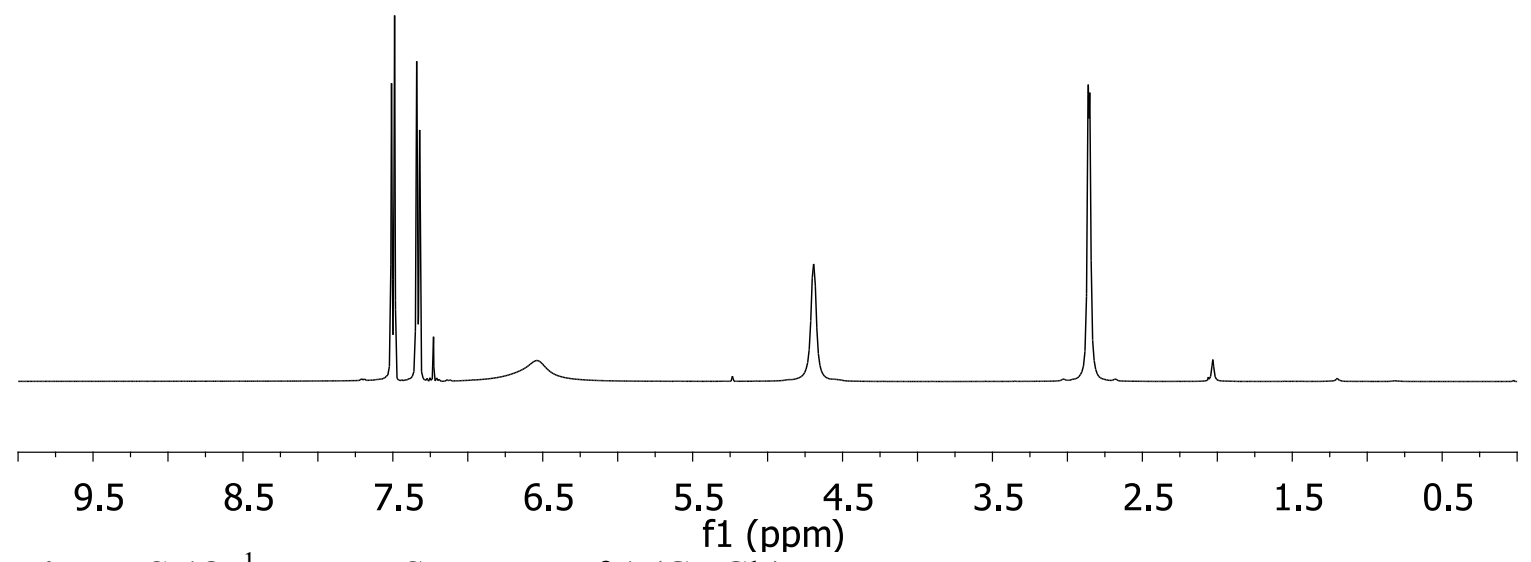

Figure S 18. ${ }^{1} \mathrm{H}$ NMR Spectrum of $\mathbf{1}\left(\mathrm{CDCl}_{3}\right)$

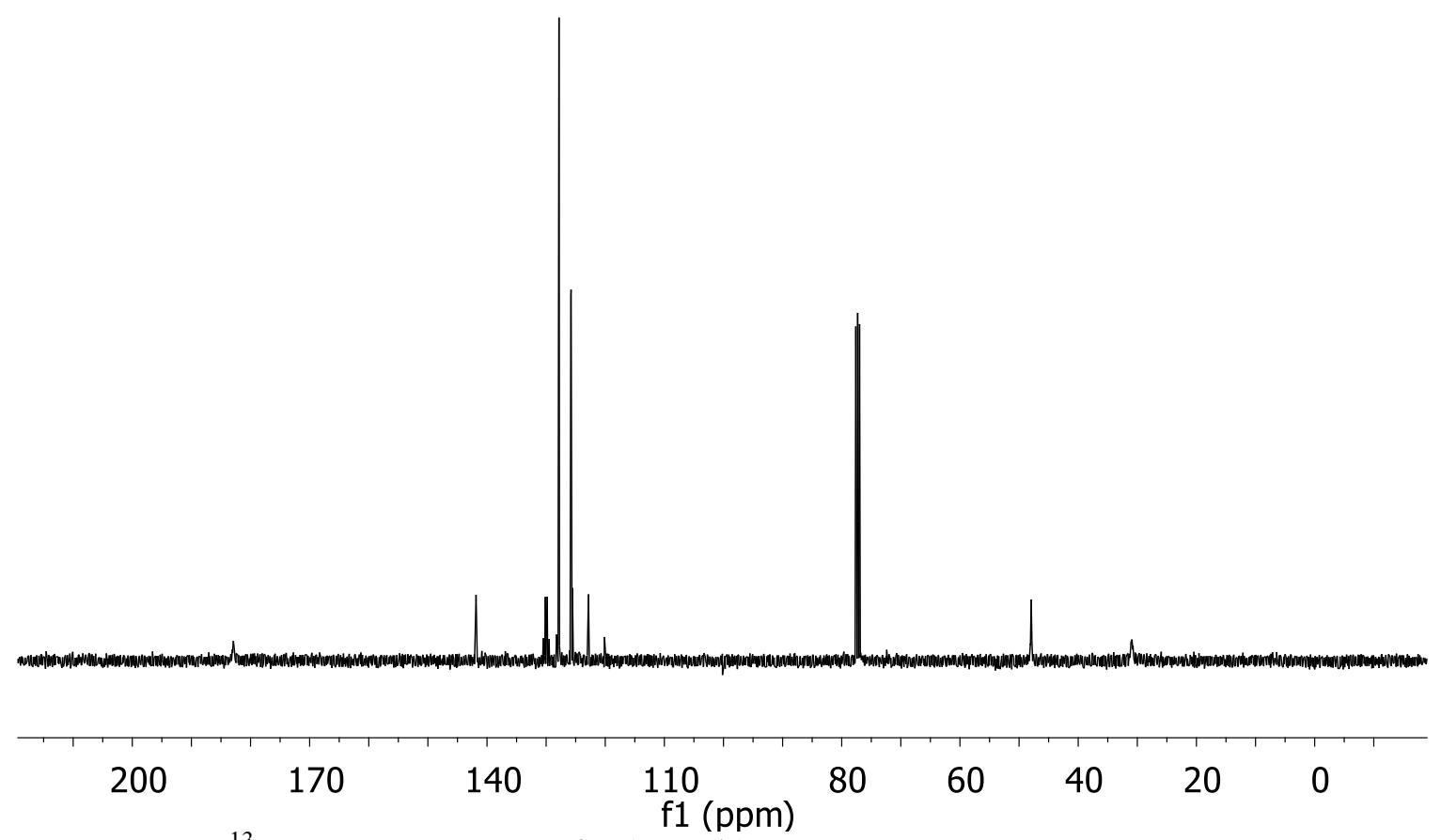

Figure S 19. ${ }^{13} \mathrm{C}$ NMR Spectrum of $\mathbf{1}\left(\mathrm{CDCl}_{3}\right)$ 


\section{ADANACEPS
MATERRALIS}

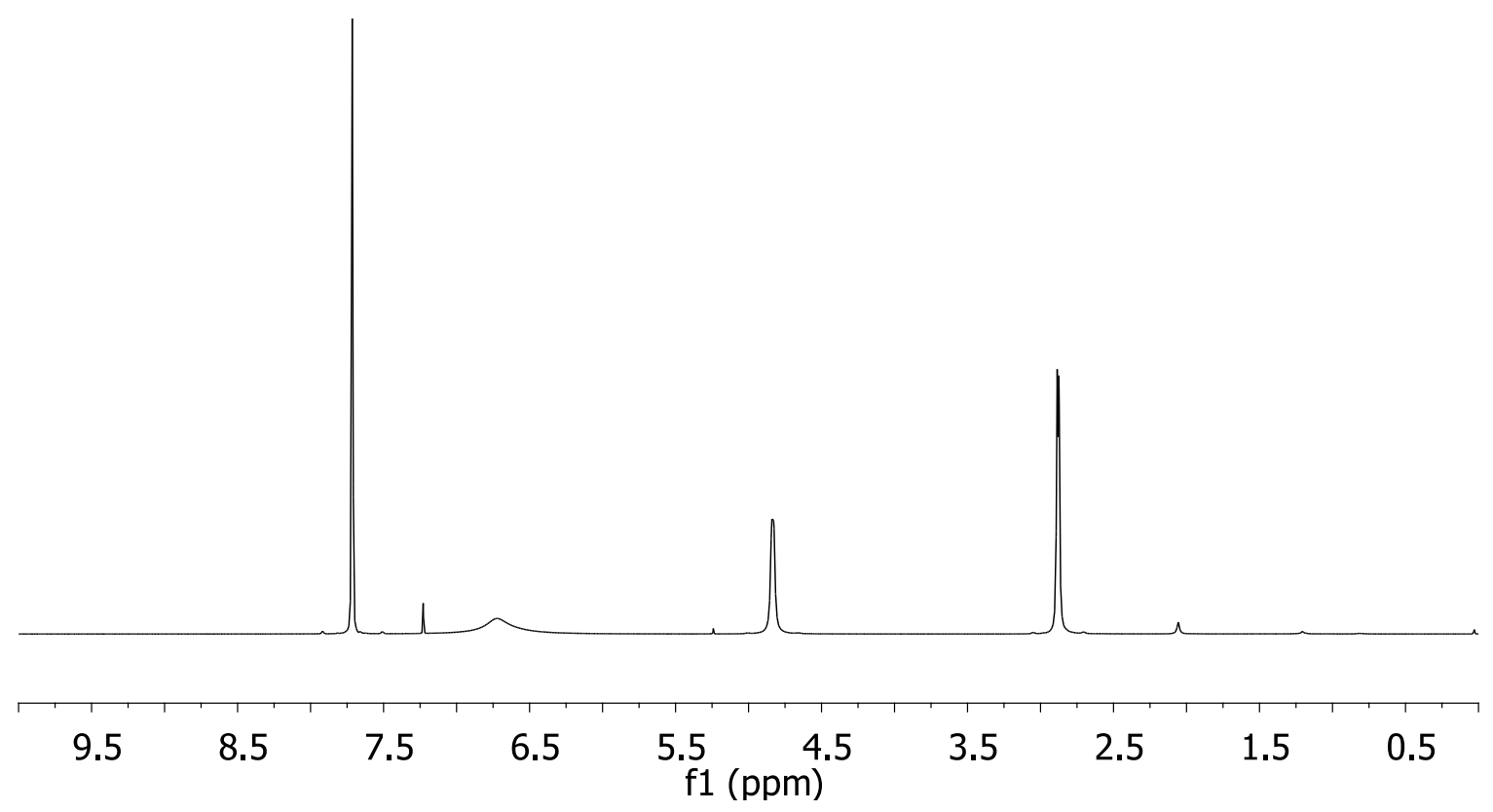

Figure S 20. ${ }^{1} \mathrm{H}$ NMR Spectrum of $\mathbf{2}\left(\mathrm{CDCl}_{3}\right)$

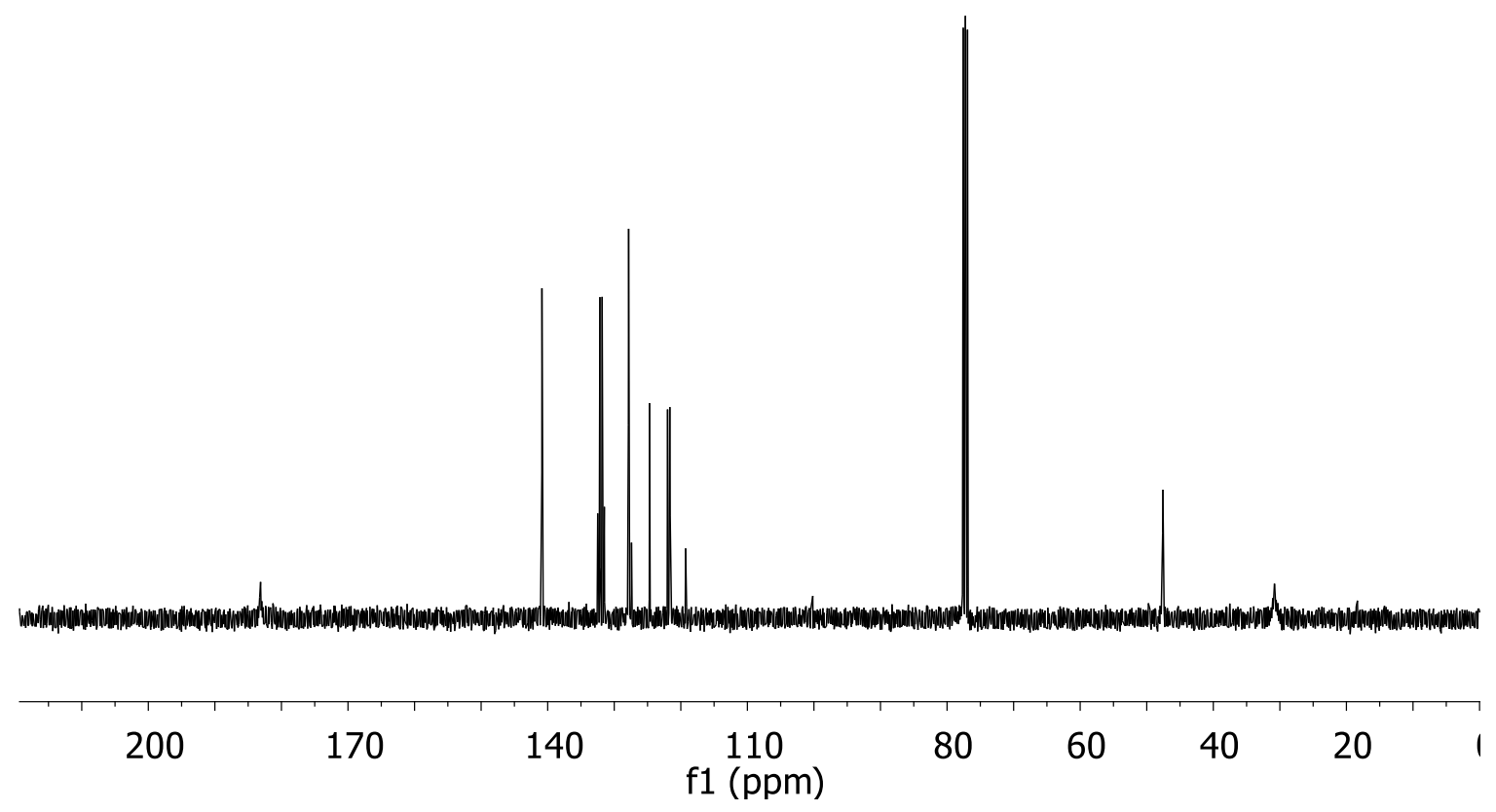

Figure S 21. ${ }^{13} \mathrm{C}$ NMR Spectrum of $2\left(\mathrm{CDCl}_{3}\right)$ 


\section{Submitted to

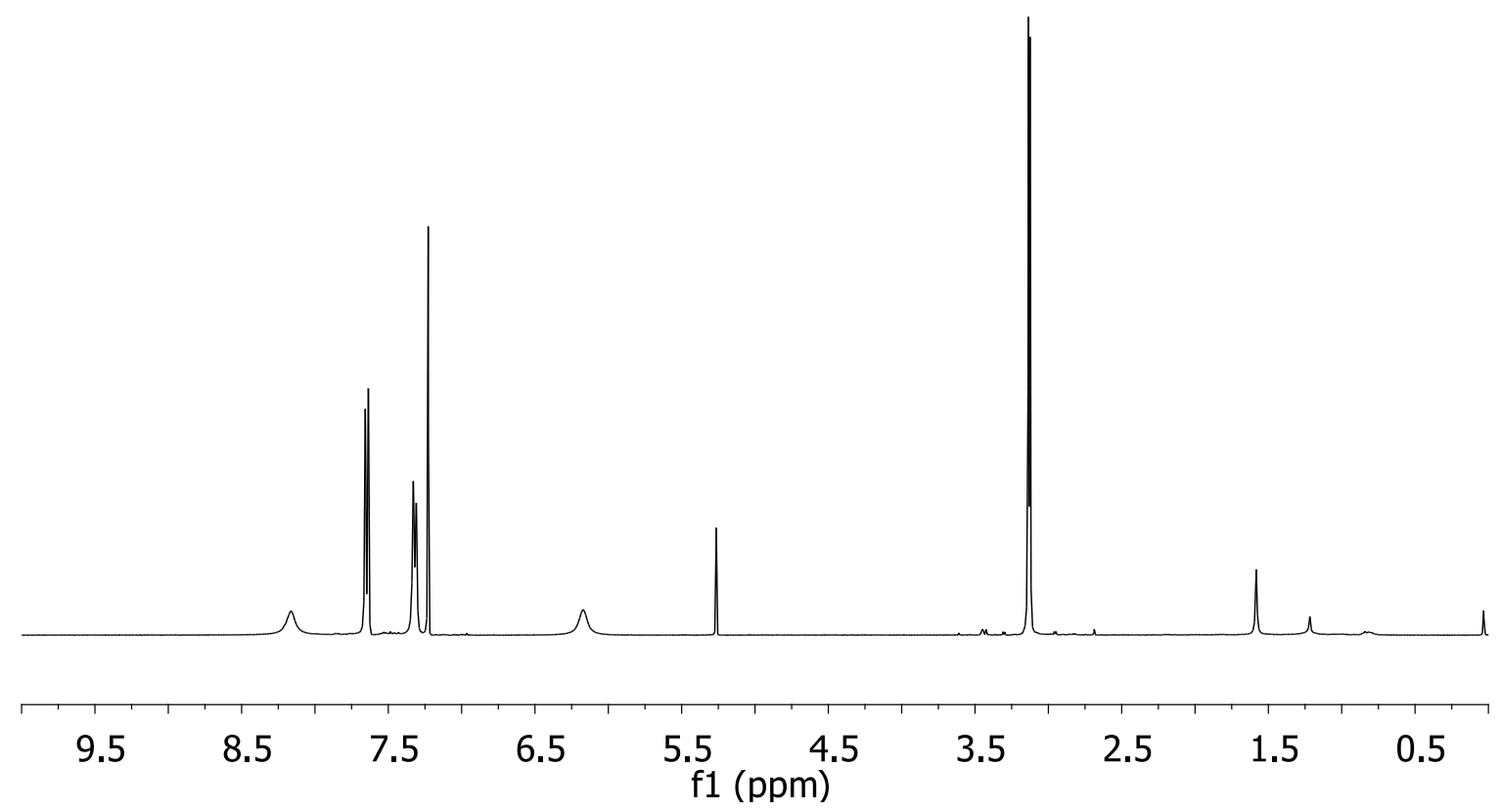

Figure S 22. ${ }^{1} \mathrm{H}$ NMR Spectrum of $3\left(\mathrm{CDCl}_{3}\right)$

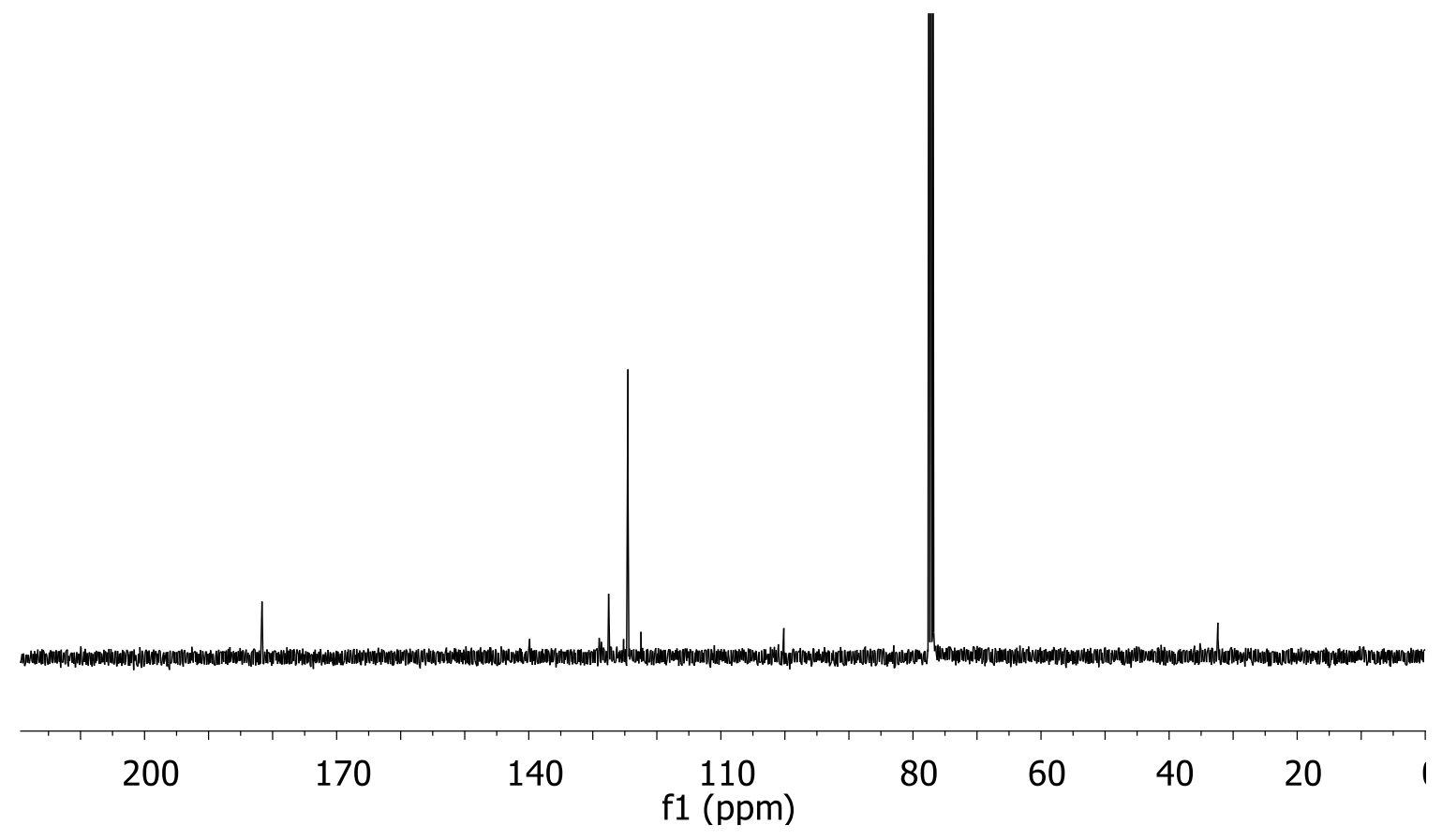

Figure $\mathbf{S} 23 .{ }^{13} \mathrm{C}$ NMR Spectrum of $3\left(\mathrm{CDCl}_{3}\right)$ 


\section{Submitted to

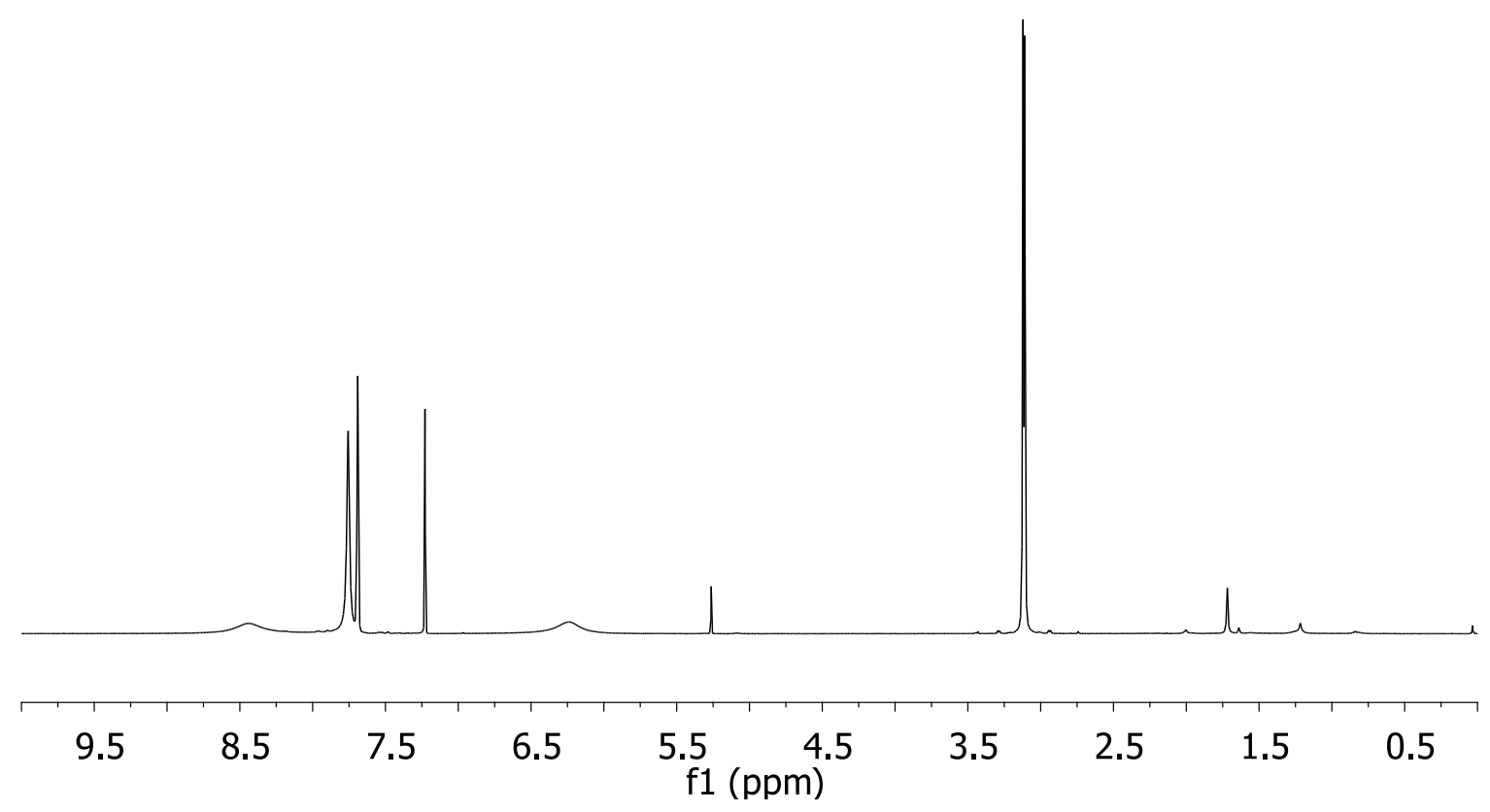

Figure S 24. ${ }^{1} \mathrm{H}$ NMR Spectrum of $4\left(\mathrm{CDCl}_{3}\right)$

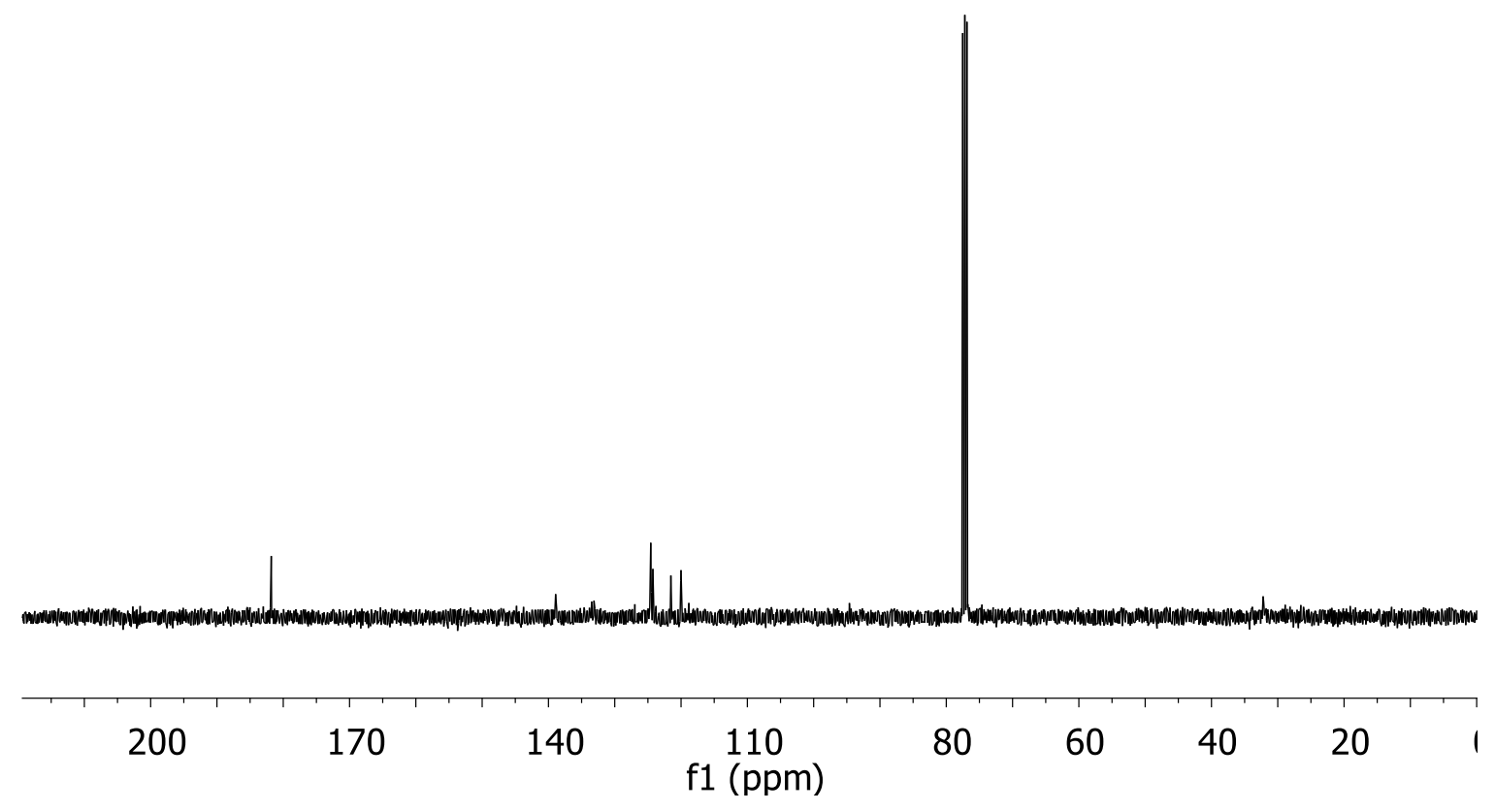

Figure S 25. ${ }^{13} \mathrm{C}$ NMR Spectrum of $4\left(\mathrm{CDCl}_{3}\right)$ 


\section{Submitted to

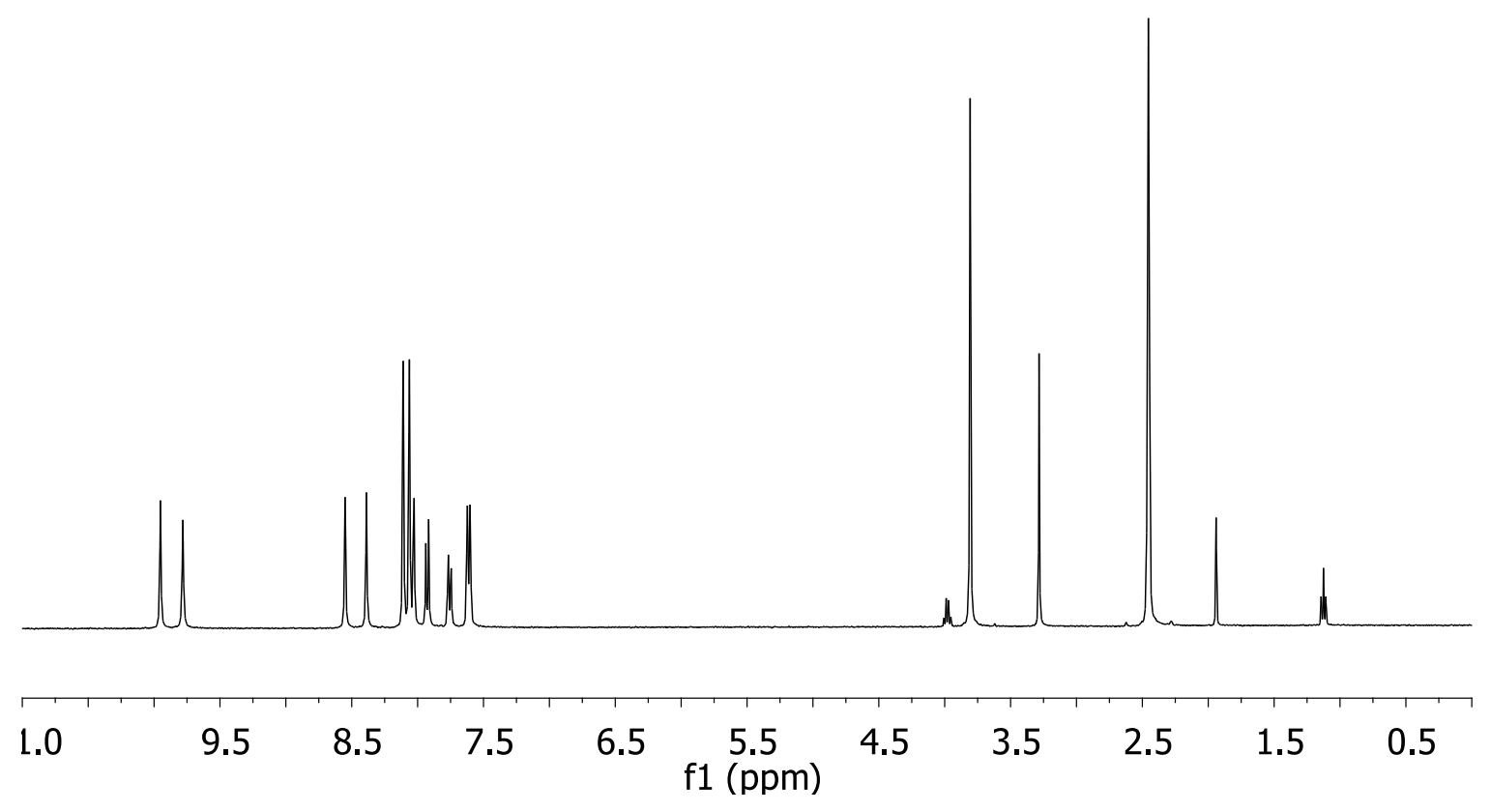

Figure S 26. ${ }^{1} \mathrm{H}$ NMR Spectrum of $8\left(\mathrm{DMSO}_{-} d_{6}\right)$

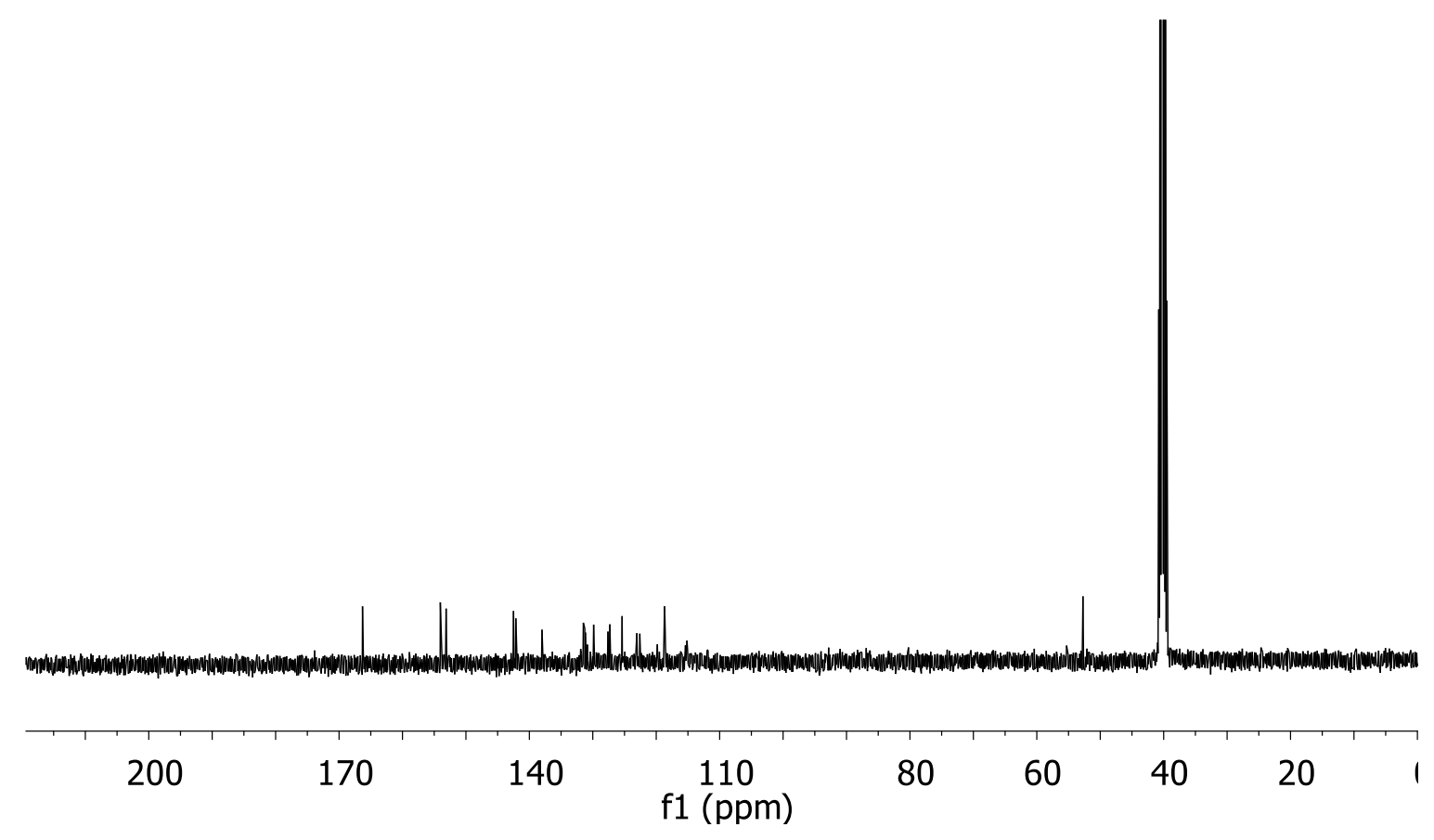

Figure S 27. ${ }^{13} \mathrm{C}$ NMR Spectrum of $8\left(\mathrm{DMSO}_{-} d_{6}\right)$ 


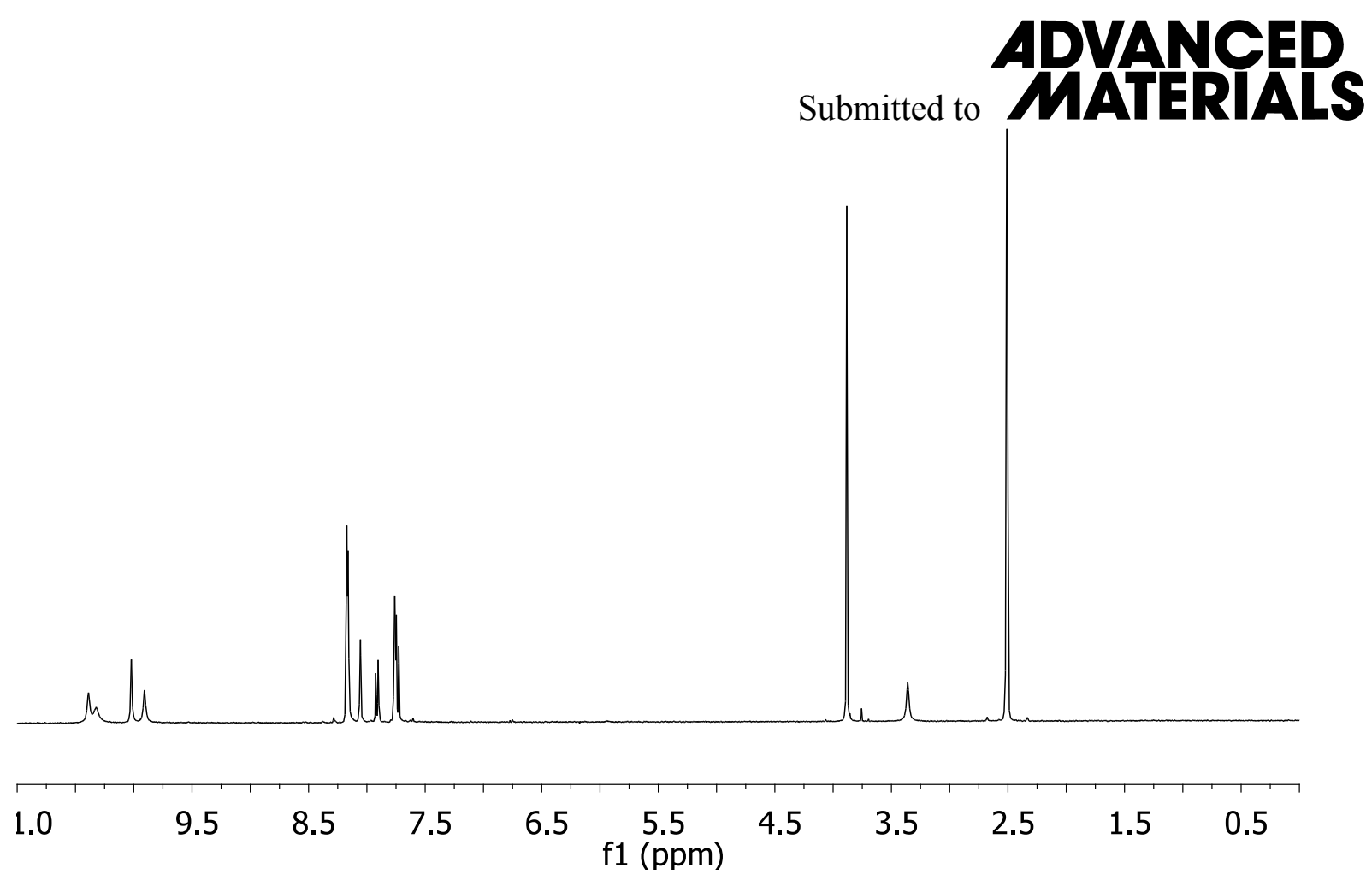

Figure S 28. ${ }^{1} \mathrm{H}$ NMR Spectrum of $9\left(\mathrm{DMSO}_{-} d_{6}\right)$

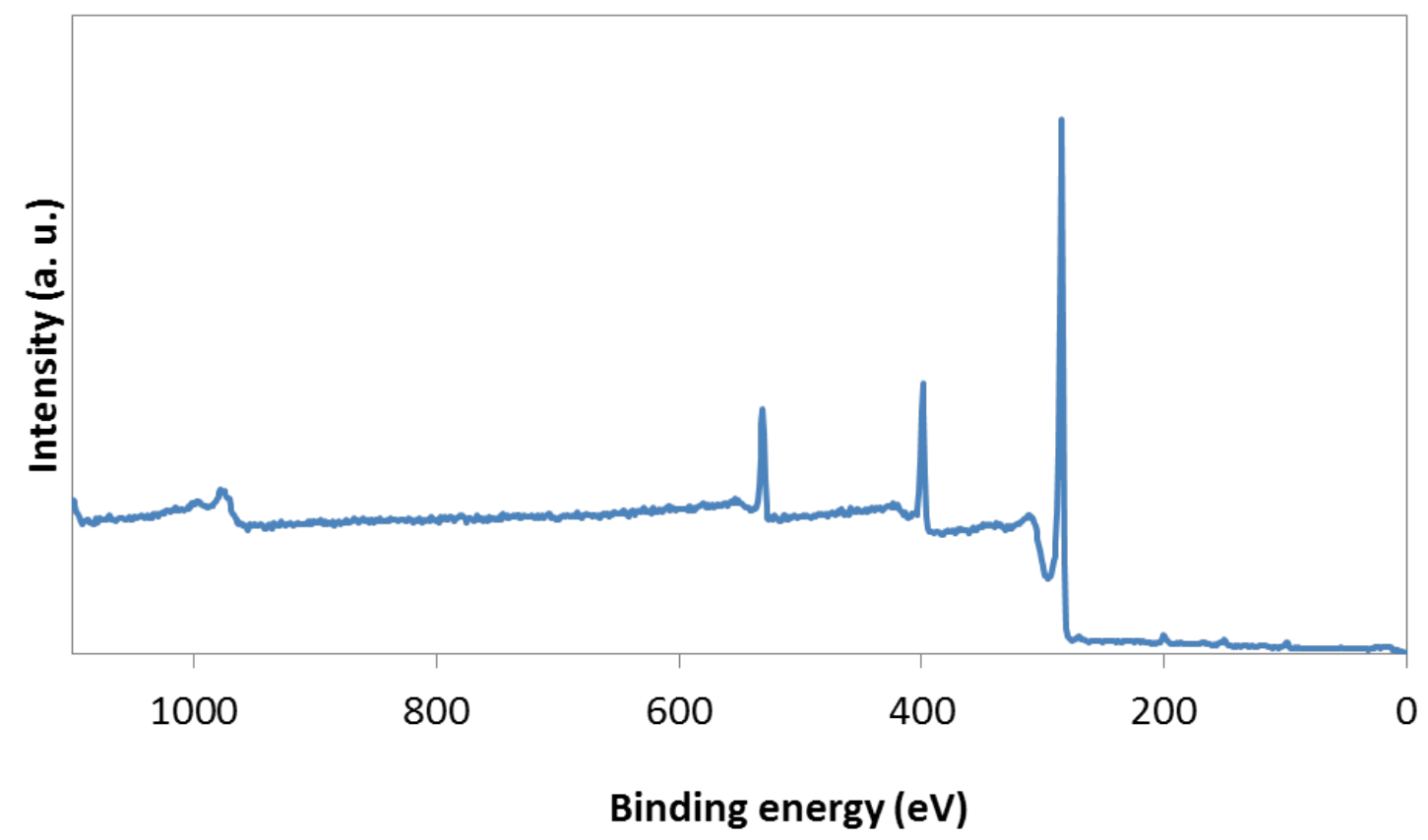

Figure S 29. XPS analysis of $\mathrm{NH}_{2}-\mathrm{SWCNT}$ 


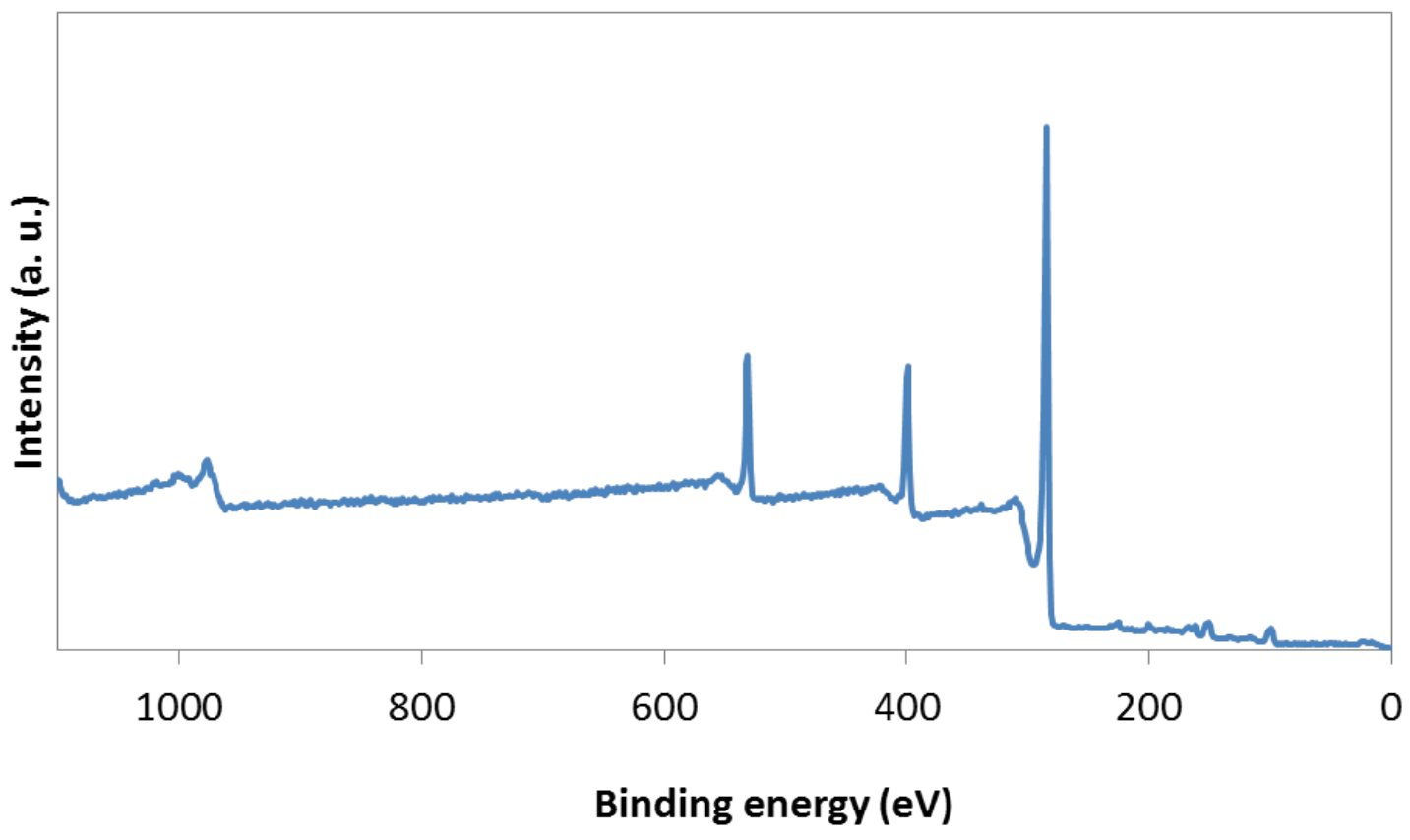

Figure S 30. XPS analysis of Me-TU-SWCNT

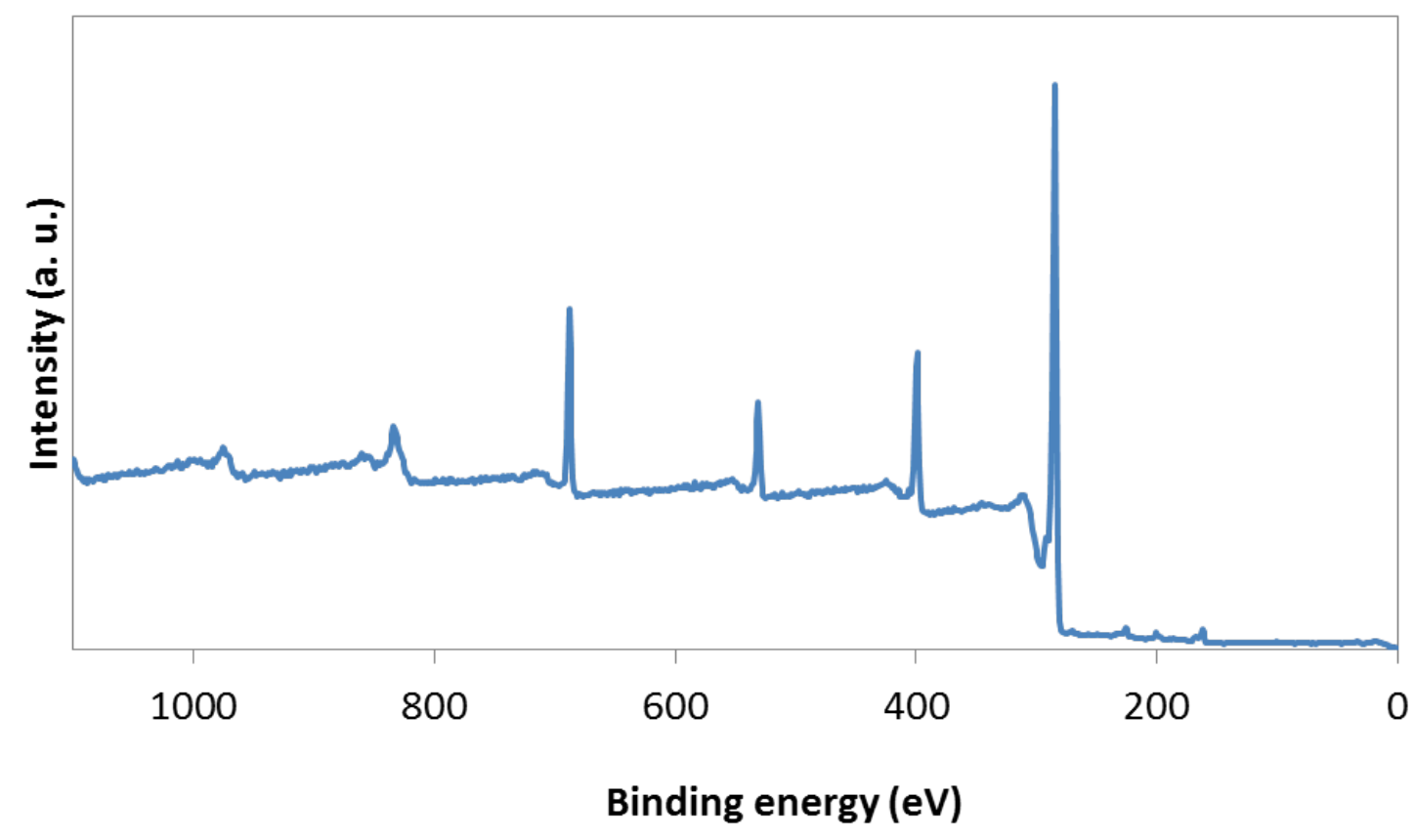

Figure S 31. XPS analysis of $\mathrm{p}-\mathrm{CF}_{3}-\mathrm{Bn}-\mathrm{TU}-\mathrm{SWCNT}$ 


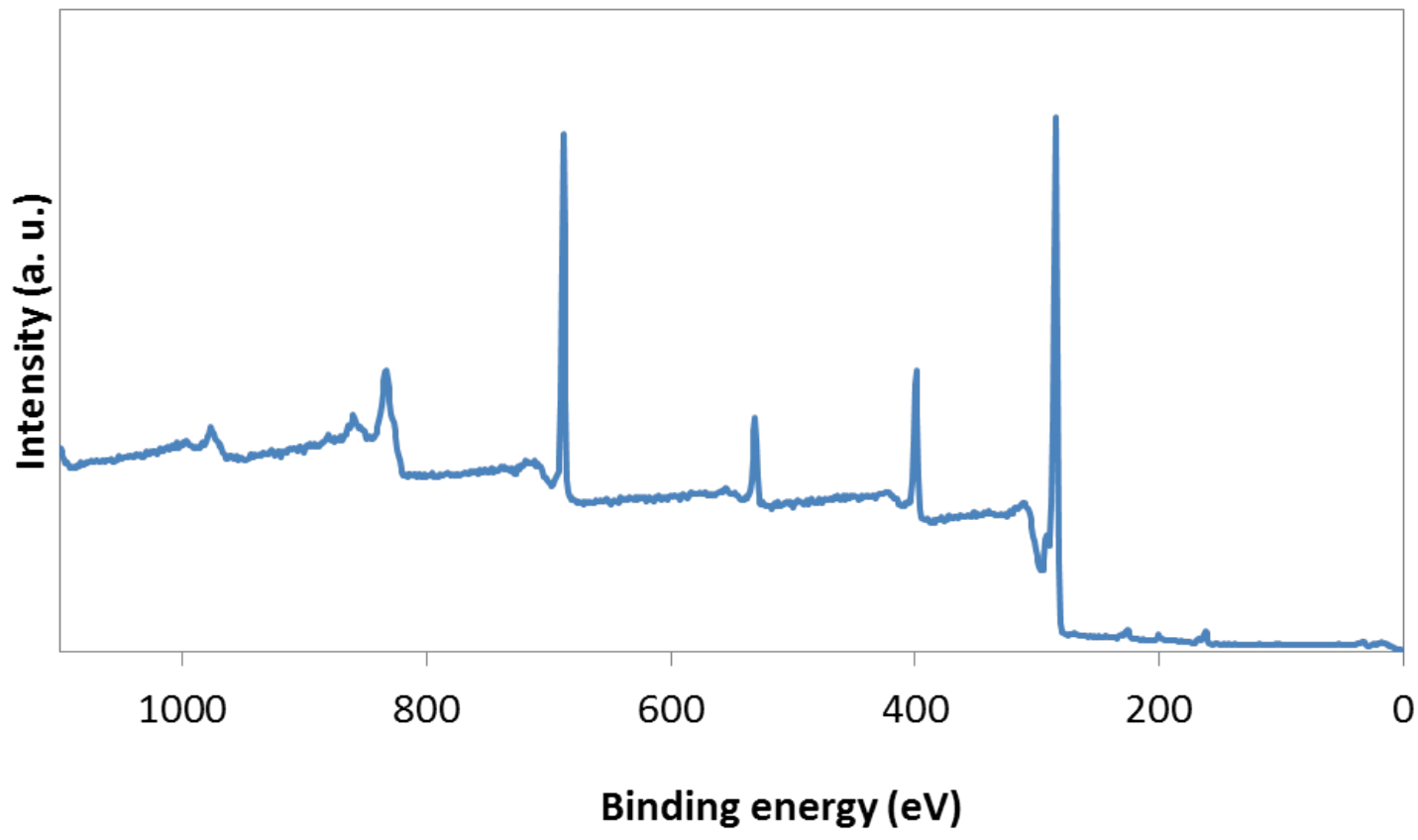

Figure S 32. XPS analysis of $\mathrm{m}-\mathrm{CF}_{3}-\mathrm{Bn}-\mathrm{TU}-\mathrm{SWCNT}$

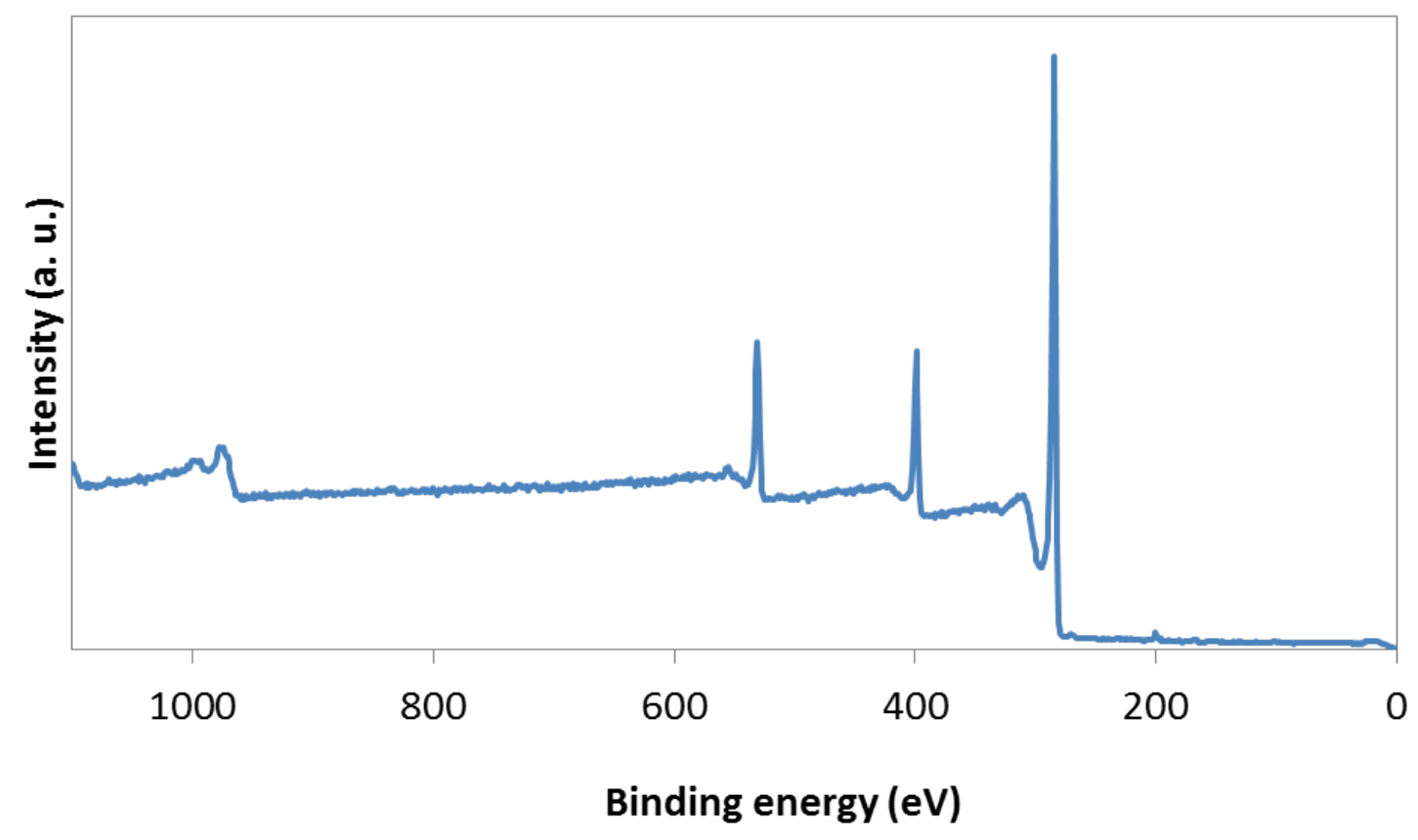

Figure S 33. XPS analysis of Me-SQ-SWCNT 


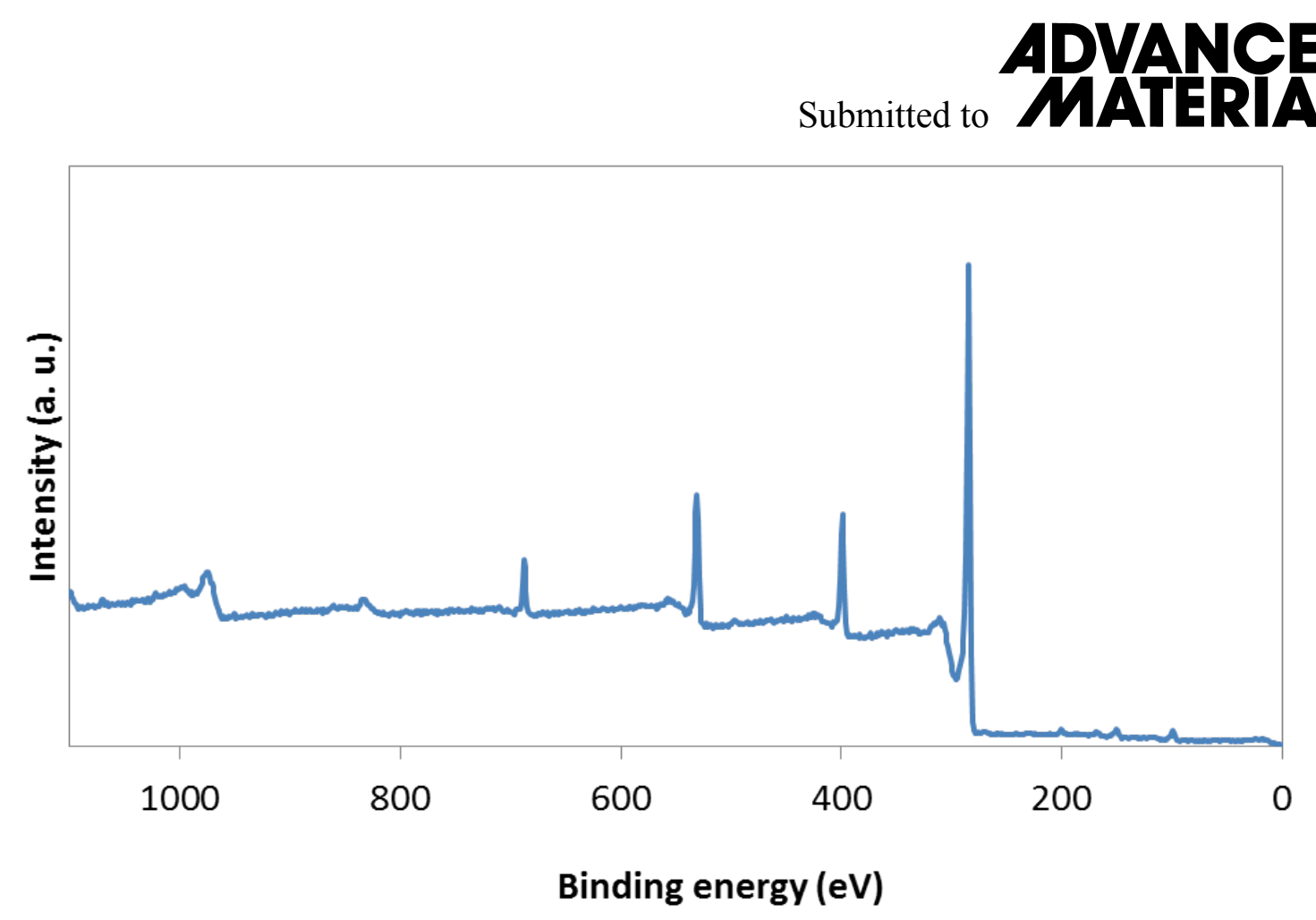

Figure S 34. XPS analysis of $\mathrm{p}-\mathrm{CF}_{3}-\mathrm{Bn}-\mathrm{SQ}-\mathrm{SWCNT}$

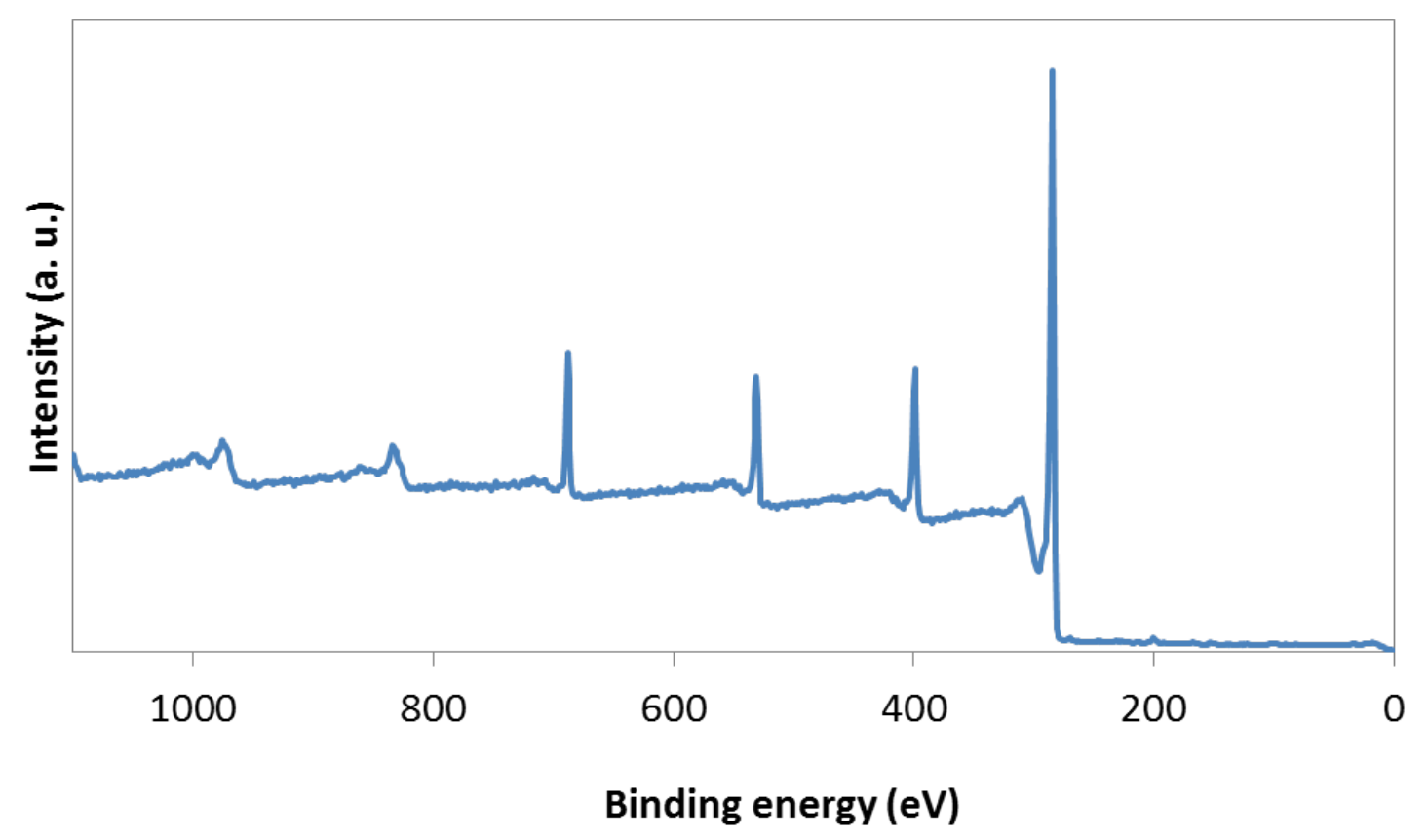

Figure S 35. XPS analysis of $\mathrm{m}-\mathrm{CF}_{3}-\mathrm{Bn}-\mathrm{SQ}-\mathrm{SWCNT}$ 


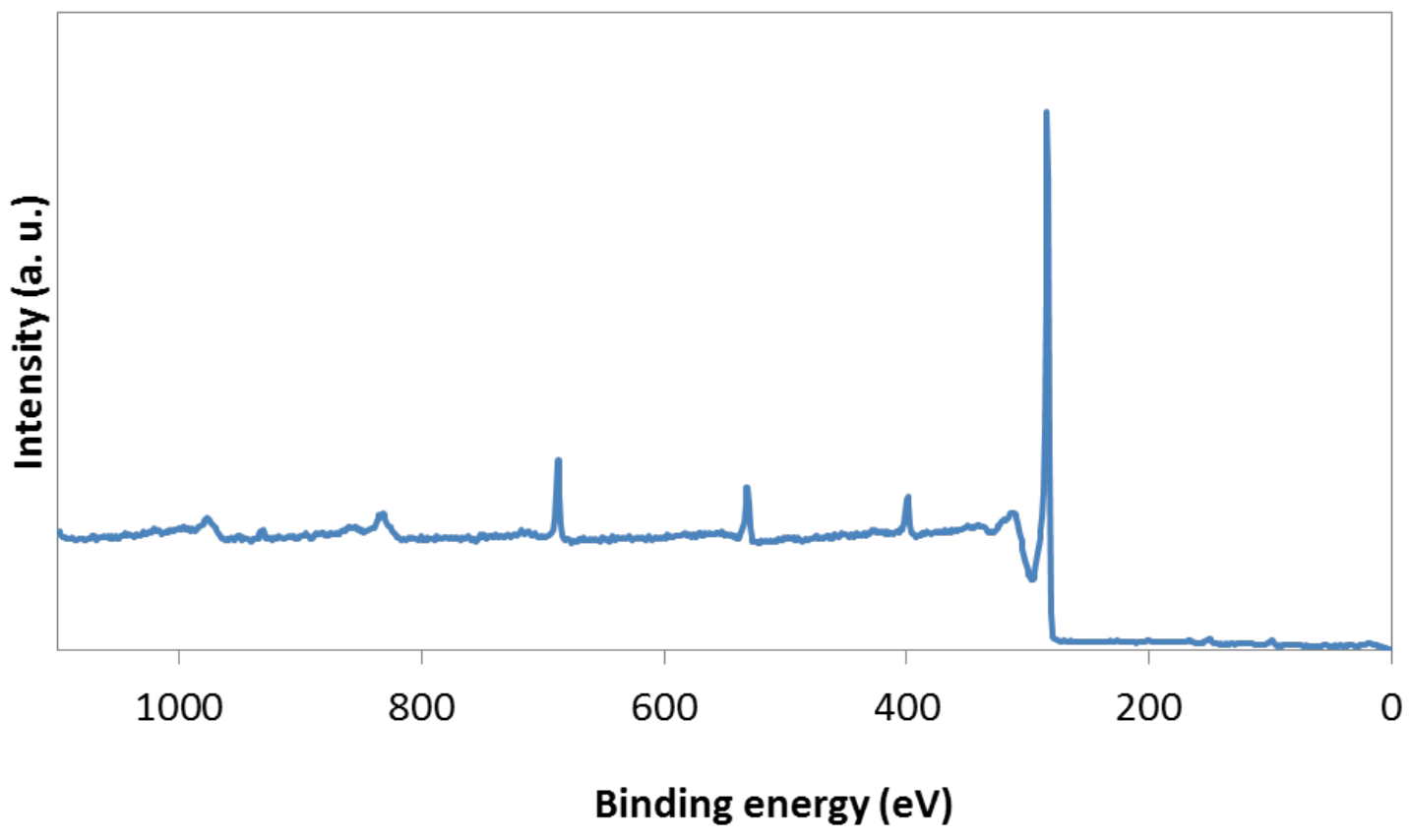

Figure S 36. XPS analysis of $\mathrm{m}-\mathrm{CF}_{3}-\mathrm{Ph}-\mathrm{TU}-\mathrm{SWCNT}$

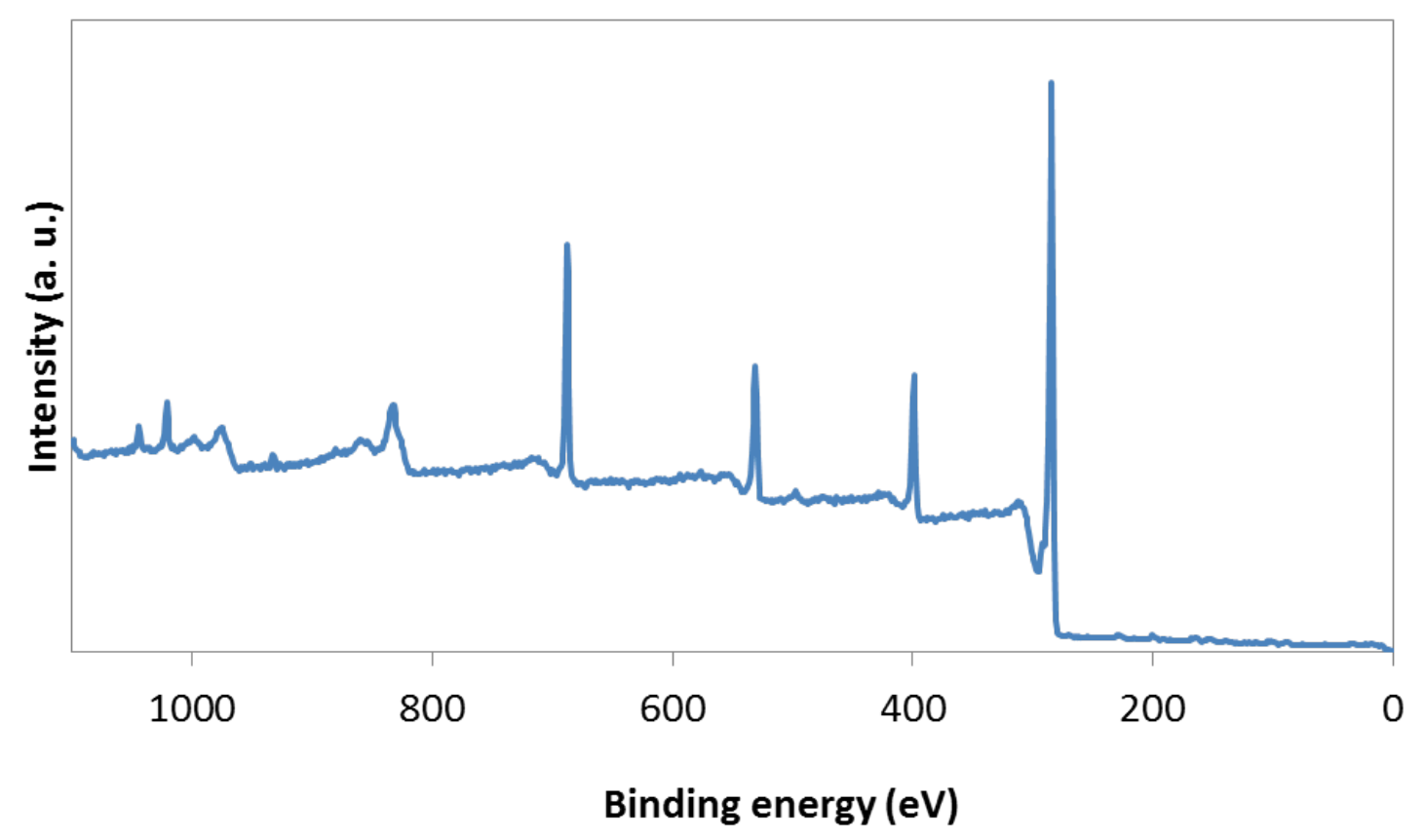

Figure S 37. XPS analysis of Bis-U-SWCNT 


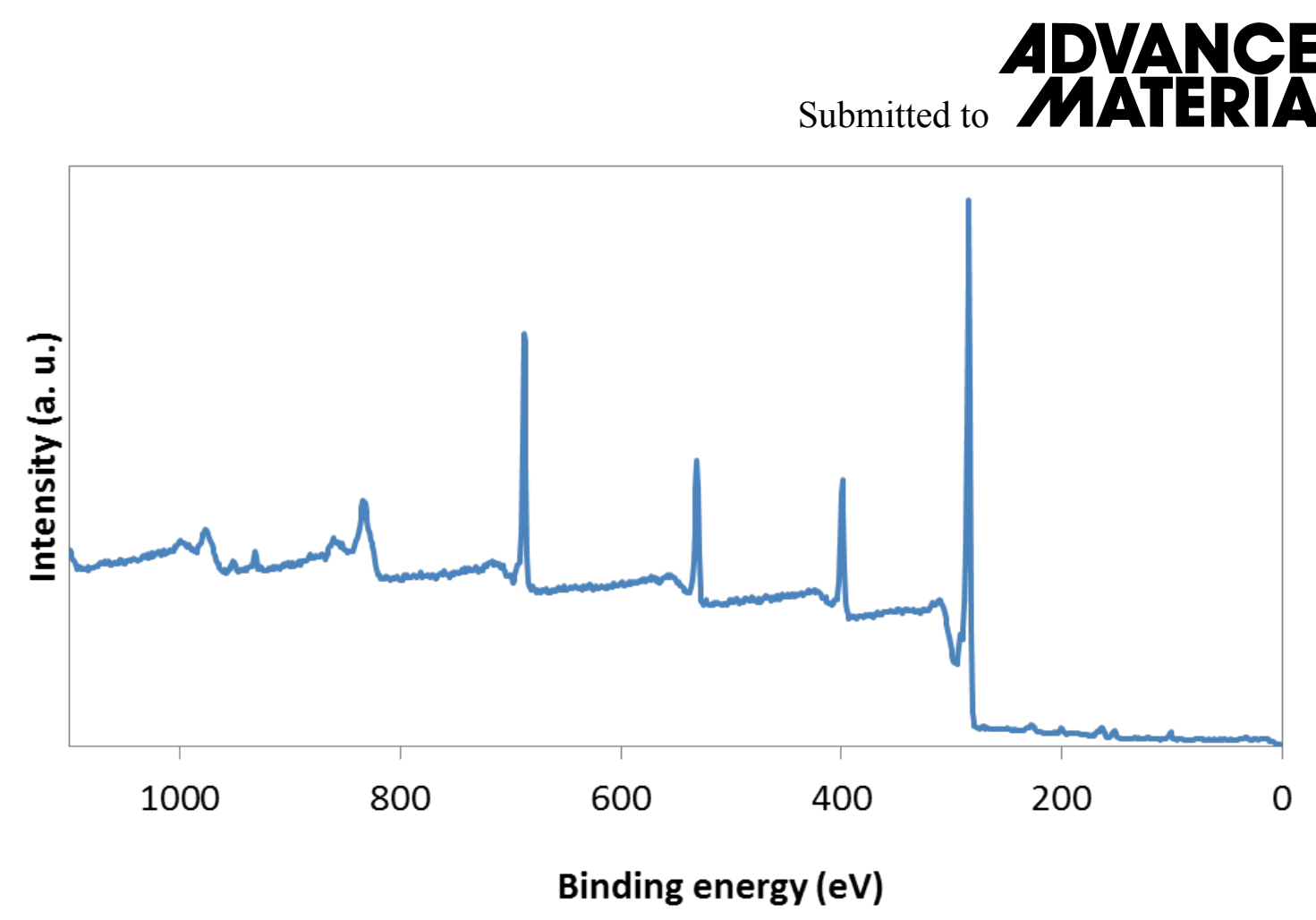

Figure S 38. XPS analysis of Bis-TU-SWCNT

References (for SI)

[1] C. Gao, H. He, L. Zhou, X. Zheng, Y. Zhang, Chem. Mater. 2009, 21, 360.

[2] H. C. Kolb, M. G. Finn, K. B. Sharpless, Angew. Chem. Int. Ed. 2001, 40, 2004.

[3] P. Dauban, R. H. Dodd, Synlett 2003, 1571. 